\title{
Review
}

Vipin Soni, Varun Goel, Paramvir Singh and Alok Garg*

\section{Abatement of formaldehyde with photocatalytic and catalytic oxidation: a review}

https://doi.org/10.1515/ijcre-2020-0003

Received January 4, 2020; accepted November 12, 2020;

published online December 14, 2020

Abstract: Formaldehyde is one of the vital chemicals produced by industries, transports, and domestic products. Formaldehyde emissions adversely affect human health and it is well known for causing irritation and nasal tumors. The major aim of the modern indoor formaldehyde control study is in view of energy capacity, product selectivity, security, and durability for efficient removal of formaldehyde. The two important methods to control this harmful chemical in the indoor environments are photocatalytic oxidation and catalytic oxidation with noble metals and transition metal oxides. By harmonizing different traditional photocatalytic and catalytic oxidation technologies that have been evolved already, here we give a review of previously developed efforts to degrade indoor formaldehyde. The major concern in this article is based on getting the degradation of formaldehyde at ambient temperature. In this article, different aspects of these two methods with their merits and demerits are discussed. The possible effects of operating parameters like preparation methods, support, the effect of light intensity in photocatalytic oxidation, relative humidity, etc. have been discussed comprehensively.

Keywords: catalytic oxidation; degradation; formaldehyde; photocatalyst.

\section{Nomenclature}

$\begin{array}{ll}E_{\mathrm{a}} & \text { Activation energy } \\ \mathrm{CO}_{2} & \text { Carbon dioxide }\end{array}$

*Corresponding author: Alok Garg, Department of Chemical Engineering, National Institute of Technology, Hamirpur, H.P. 177005, India, E-mail: alok.garg.chem@gmail.com

Vipin Soni and Varun Goel, Department of Mechanical Engineering, National Institute of Technology, Hamirpur, H.P. 177005, India Paramvir Singh, Combustion Research Laboratory, Aerospace Engineering Department, Indian Institute of Technology Bombay, Mumbai 400076, India

\begin{tabular}{ll} 
CD & Colloidal deposition \\
CP & Colloidal precipitation \\
DRIFTS & Diffused Fourier transform infrared spectroscopy spectra \\
DOM & Dimensionally order microporous \\
ev & Electron volt \\
$E-R$ & Eley-Rideal \\
FBR & Fixed bed reactor \\
GHSV & Gas hourly space velocity \\
IMP & Impregnation \\
ID & Inner diameter \\
L-H & Langmuir-Hinshelwood \\
LSP & Long six pyramids \\
MVK & Mars-Van krevelan \\
OMS & Octahedral molecule sieve \\
PM & Particulate matter \\
ppm & Parts per million \\
PCO & Photocatalytic oxidation \\
RH & Relative humidity \\
SEM & Scanning electron microscopy \\
SSP & Short six pyramids \\
SBS & Sick building syndrome \\
SP & Six prism \\
TEM & Transmission electron microscopy \\
VOC & Volatile organic compound \\
vol & Volume \\
$\lambda$ & Wavelength \\
\hline
\end{tabular}

\section{Introduction}

Most of the people spend their time at shopping center, home, car and office, etc. Sometimes, there are more pollution levels indoors compared to outdoors. The common indoor air pollutants are volatile organic compounds (VOCs), carbon oxides $\left(\mathrm{CO}\right.$ and $\left.\mathrm{CO}_{2}\right)$, nitrogen oxides $\left(\mathrm{NO}_{x}\right)$, and particulate matter etc. The possible ways of emission of VOC are from chemical industrial plants, transportation, painting, electroplating, etc. (Wang, Ang, and Tade 2007). There are several origins inside the indoor which contaminate the air. Due to the adverse effect of these contaminants a term "Sick building syndrome (SBS)" has used for the buildings. Filtration and proper ventilation are commonly used for the purpose of the solution to indoor air pollutants as per the typical technology. But hazardous effects arise due to the microbiological and VOC contamination of air (Goswami 1999a). 
So, for restraining pollution inside the building, several techniques have used like air exchange rate and the recent one is by using air purifiers. These air purifiers generally use the filters to remove the particulate matters or sorption material to adsorb odors or gases. But these techniques are not much efficient because they can't eliminate them completely (Zhao and Yang 2003). VOCs e.g. benzene, formaldehyde (HCHO), xylene, and toluene are always discharged in both outdoor and indoor environments through various methods. Long-time divestment to contaminated surroundings though having a very few ppm of VOCs may source of long term sicknesses (Tang et al. 2006a). As per the various health agencies, VOCs are measured as a carcinogenic chemical for human being and longtime contact leads to diseases such as asthma and caused decrement in functioning of pulmonary part. Also, long time expose to formaldehyde can leads to nasopharyngeal cancer.

These VOCs have a very close relationship with sick building syndrome which is an important term used by occupants to represent reduced comfort or health. Fresh painting indoor may produce diseases like asthma (Norbäck, Edling, and Wieslander 1994). A little amount of HCHO can be hazardous to human being in case of long term aspects which produces serious health problems like nasal tumors, skin irritation, mucous membranes irritation of eyes etc. (Li et al. 2016a). In addition, the release of VOCs to the environment can form ozone layer depletion, urban smog in the greenhouse effect and the stratosphere (Liang, Li, and Jin 2012). The cumulative investigation is needed to overwhelmed hazards by VOCs to human healthiness and our environment has caused fast appreciation of toxic aspects of VOCs throughout the past two decades (Goode 1985). It is significant to change injurious volatile organic compounds (VOCs) into the environment-sociable compounds. Various methods have been proposed for reduction of VOCs like physical adsorption (Domingo-Garcia et al. 1999; Matsuo et al. 2008), plasma technology (Liang et al. 2010), plant absorption (Xu et al. 2010; Terelak et al. 2005), photocatalysis (Akbarzadeh et al. 2010; Fu, Zhang, and Li 2011; Li et al. 2010; Photong and Boonamnuayvitaya 2009), and catalytic oxidation (Hu et al. 2015; Sekine 2002; Tang et al. 2006b).

Inside airstream can contain other hazardous contamination like microorganisms (Goswami 1999a). A combination of electrostatic precipitation and photocatalytic oxidation (PCO) has been found as an interactive effect to destroy contamination of air by the microorganism. Removal of microorganism can be done through the electrostatic precipitation. It brings microorganism on the surface coated with photocatalyst (Goswami 1999b). Unlike many other contaminants in indoors which can satisfactorily have diminished by many processes applied, formaldehyde can't be correctly measured just due to its higher vapor pressure i.e. $3883 \mathrm{~mm}$ $\mathrm{Hg}$ at room temperature i.e. $25^{\circ} \mathrm{C}$ and relatively very low boiling point temperature i.e. $-19.3^{\circ} \mathrm{C}$ (Pei and Zhang 2011). Subsequently catalytic oxidation process needed decreased temperature for degradation of $\mathrm{HCHO}$, the current investigation is grounded on a catalyst for the complete oxidation at environmental conditions. The possible main sources of $\mathrm{HCHO}$ emissions are industries, building materials, and transportation (vehicles running by mainly diesel engine) (Singh and Chauhan 2016). Conventional methods, like using filters to remove the contaminants or by sorption materials (like granular activated carbon) to absorb various VOCs are the methods that can only decrease concentration of contaminants in environments. These methods can only alter the stage of the contaminants relatively than the removing them entirely. For HCHO degradation various methods have been reported including (a) chemisorption (b) biological/botanical filtration (c) thermal and non-thermal catalytic oxidation, (d) plasma decomposition with or without using catalyst, and (e) photocatalytic oxidation (PCO).

Plasma cluster ions generated by plasma disintegration process also has the capacity to degrade the HCHO. Generation of plasma is simply through electronic and photoionization the targeting factor through plasma process are density of ion, processing timing, and arrangement of chemicals (Ding et al. 2006). Byproducts and small amount of $\mathrm{HCHO}$ are the restriction of plasma technology. Plasma catalyst degradation of $\mathrm{HCHO}$ is sometimes problematic due to over formation of ozone (Yuan et al. 2020). In current time botanical filtration is also investigated for degradation of HCHO (Wu et al. 2003). For adsorption of HCHO, biomass bricks are also analyzed and have given an alternate option for diminishment (Zhang et al. 2019). Modified photocatalytic oxidation (PCO) is also a good removal technique for HCHO. Traditional UV light has replaced by visible light in latest $\mathrm{PCO}$ for the diminishing HCHO. For diminishment of $\mathrm{HCHO}$, the most suitable photocatalyst $\mathrm{TiO}_{2}$ with varying absorption of noble metal (Pt, $\mathrm{Au}, \mathrm{Pd}, \mathrm{Ag}$, etc.) and oxides of transition metal are generally used. $\mathrm{Zhu}$ and $\mathrm{Wu}(2015)$ has used $\mathrm{Pt} / \mathrm{TiO}_{2}$ photocatalyst for abatement of $\mathrm{HCHO}$.

In this review, there is a thorough description of the photocatalytic oxidation and thermal and non-thermal catalytic oxidation for the degradation of $\mathrm{HCHO}$ due to their merits among all mentioned process.

\section{Photocatalytic oxidation process}

A typical PCO process consists of light energy companionship of water vapor. Water vapors are used for production of 
necessary hydroxyl radicals to diminish the VOCs and microbes (Goswami 2003). Water vapour and carbon dioxide $\left(\mathrm{CO}_{2}\right)$ are the harmless byproducts of degradation of VOCs using PCO process with semiconductor (Tompkins 2001). The aforementioned ability of PCO attained focus which generally destroys the hydrocarbons with the use of $\mathrm{TiO}_{2}$ photocatalyst. For regulation of $\mathrm{CO}_{2}$ i.e., regulated emission there is a carbon dioxide cycle available in nature to balance the concentration of $\mathrm{CO}_{2}$ in the environment but for the VOCs, there is no such cycle available (Singh and Chauhan 2016). A patent has been filed for disinfecting the indoor air from the clothes, curtain, coverings, etc. and used it for producing the pure air of heating, ventilating, and air conditioning systems (Goswami 2008).

This invention is based on the PCO process in that it uses lightening the surface of photocatalyst with the origin of photons. The photocatalytic oxidation process combines water, oxygen, and VOCs on the catalyst surface to produce $\mathrm{H}_{2} \mathrm{O}$ and $\mathrm{CO}_{2}$ under light radiation. Researchers have used nano Titania $\left(\mathrm{TiO}_{2}\right)$ widely as a catalyst which is activated by light energy. Titania has been proven as effective photocatalyst. Photocatalysis technology using $\mathrm{TiO}_{2}$ has sufficient potential for the purification of organic pollutants and wastewater (Hashimoto, Irie, and Fujishima 2005; Hoffmann et al. 1995; Wu et al. 2003). There are further several photocatalysts which have been used for degradation of $\mathrm{HCHO}$ which are $\mathrm{ZnO}, \mathrm{Al}_{2} \mathrm{O}_{3}$, $\mathrm{ZrO}_{2}, \mathrm{WO}_{3}, \mathrm{SnO}_{2}, \mathrm{CeO}_{2}, \mathrm{ZnS}, \mathrm{Fe}_{2} \mathrm{O}_{3}$ and $\mathrm{CdS}$ (Hoffmann et al. 1995). But the most popular photocatalyst used for oxidation of formaldehyde into harmless gases is $\mathrm{TiO}_{2}$ and $\mathrm{ZnO}$. $\mathrm{TiO}_{2}$ is the readily available, relatively inexpensive, chemically stable element. Holes generated by photo-oxidation process are highly oxidizing in nature (Jin et al. 2007).

$\mathrm{Fe}_{2} \mathrm{O}_{3}-\mathrm{TiO}_{2}$ supported with $\mathrm{Pt}$ doping is also an excellent catalyst for the decomposition of formaldehyde (Yang et al. 2000). $\mathrm{TiO}_{2}$ doped with $\mathrm{Ag}$ metal also shows enhanced photocatalytic activity for the devastation of bacterial spores as a comparison to typical photocatalysis (Vohra et al. 2005). Arranging the photocatalysts into the active catalysts between $\mathrm{Ti}, \mathrm{Zn}$, and tungsten; the result shows that: $\mathrm{TiO}_{2}$ (anatase) $<\mathrm{ZnO}<\mathrm{WO}_{3}$. There is generally two crystal form of $\mathrm{TiO}_{2}$ available: anatase and rutile. The difference between these two structures is of band gaps. The band gaps of anatase and rutile phases are 3.23 and $3.02 \mathrm{ev}$ respectively.

\subsection{Working principle}

When $\mathrm{TiO}_{2}$ is irradiated by light, electron and hole pairs are generated in the bulk particle. While producing holes, electrons gain energy to leave from valence band to conduction band with crossing the band gap. The holes in valence band have great oxidative power and due to this, it makes hydroxyl radicals with reaction of absorbed hydroxide ions. This formation process is accountable for photo oxidation of $\mathrm{HCHO}$. But alone $\mathrm{TiO}_{2}$ has the restriction in case of application because of requirement of UV light and lesser solar radiation coming to Earth surface. Although this restriction has been eliminated by expansion of optical retaliation of $\mathrm{TiO}_{2}$ up to visible light from UV. These UV lights are harmful to the human body. Decomposition through irradiation of light on catalyst surface is shown in Figure 1.

Electrons and holes permit oxidation and reduction on the photocatalyst surface (Ohtani 2008). The corresponding equation of generation of holes and electron due to irradiation of photon can be written as:

$$
\mathrm{TiO}_{2}+\text { photons } \rightarrow \text { electron }\left(e^{-}\right)+\operatorname{hole}\left(h^{+}\right)
$$

In above reaction process, holes are responsible for oxidation process while electrons for reduction which is also shown in Figure 2.

$$
\begin{gathered}
\text { Oxidation reaction : hole }\left(h^{+}\right)+\mathrm{OH}^{-} \rightarrow \mathrm{OH}^{*} \\
\text { Reduction reaction }: e^{-}+O_{\text {2ads }} \rightarrow O_{\text {2ads }}-
\end{gathered}
$$

The role of hydroxyl radical $\left(\mathrm{OH}^{\star}\right)$ is important as formaldehyde gas is passed through the photocatalytic oxidation device, it oxidizes the gaseous $\mathrm{HCHO}$ into harmless $\mathrm{CO}_{2}$ and $\mathrm{H}_{2} \mathrm{O}$. These hydroxyl radical generally derived from oxidation of water vapor or adsorbed hydroxyl anion.

Different activity during the PCO has various advantages (Ollis 2000);

- It is recognized as the safe process which commonly uses the anatase $\mathrm{TiO}_{2}$ as a photocatalyst, an $n$-type semiconductor found also in some toothpaste and pharmaceutical suspensions.

- During the oxidation process, final source of oxygen is molecular oxygen which is a safer oxidant as compared to hydrogen peroxide or ozone etc.

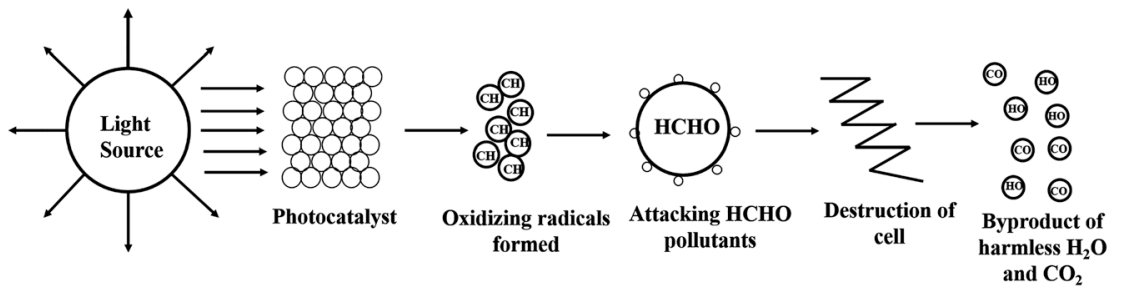

Figure 1: Formaldehyde degradation due to irradiation of light on catalyst surface. 


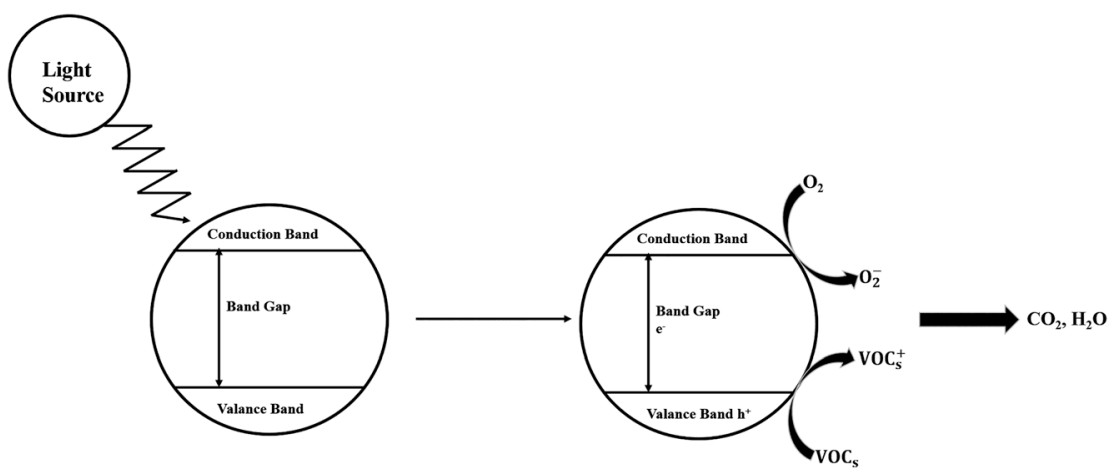

Figure 2: Process of generation of electron and holes in conduction and valence band.
- The photocatalysis process generally requires room temperature.

- As mentioned above hydroxyl radicals are photogenerated in the surface of Titania which is simpler process since there are many mechanisms available for the oxidation process.

UV-Vis light is responsible for the creation of electronholes pairs in the photocatalyst during PCO of VOCs.

\subsubsection{UV responsive photocatalysts}

Emphasize on different types of defects in $\mathrm{TiO}_{2}$ like surface oxygen vacancies, $\mathrm{Ti}$ interstitials and oxygen atoms for high impact on the photo-dissociation of HCHO. These defects have a high impact on the thermal excitation of oxygenated organic compounds on $\mathrm{TiO}_{2}$ (Benz et al. 2009; Bowker and Bennett 2009; Landis et al. 2012; Li and Diebold 2009; Lu, Linsebigler, and Yates 1994; Wang et al. 2003; Zhang et al. 2007). Due to wide energy bandgap titanium oxide activates only through ultraviolet (UV) region. $\mathrm{TiO}_{2}$ is activated through the irradiation of photon $(h v)$ on the surface with ultra-band energy from the UV light source. Formation of electrons and holes caused oxidation of absorbed toxic organic pollutants and form $\mathrm{CO}_{2}$ and $\mathrm{H}_{2} \mathrm{O}$ (Zou et al. 2006). All the literature tills now had shown that the surface of noble metal sides has the most active site for the oxidation process of HCHO (Kecskés, Raskó, and Kiss 2004). In different semiconductor materials, $\mathrm{ZnO}$ has bandgap relatively equal to $\mathrm{TiO}_{2}$ (Xu and Schoonen 2000) and the origin of $\mathrm{ZnO}$ is quite wide. But $\mathrm{UV}$ activation of $\mathrm{ZnO}$ was not easy till suitable morphological differences invented. It is quite understood that defects influenced the photocatalysis (Gupta, Barick, and Bahadur 2011; Shi et al. 2011). Therefore, by improving the morphologies and the defects in $\mathrm{ZnO}$ enhance the photocatalytic properties. UV activation of $\mathrm{ZnO}$ enhances by etching the sample with Argon (Ar) (Liao et al. 2013). The $254 \mathrm{~nm}$ wavelength UV lamp emitted higher photons which have contributed efficient degradation of $\mathrm{HCHO}$ over $\mathrm{TiO}_{2} / \mathrm{UV}$. Doping of silver (Ag) or cerium (Ce) ions could enhance photocatalytic property of $\mathrm{TiO}_{2}$. The degradation of $\mathrm{HCHO}$ over $\mathrm{Ce}-\mathrm{TiO}_{2}, \mathrm{Ag}-\mathrm{TiO}_{2}$, and $\mathrm{TiO}_{2}$ can be arranged in order of $\mathrm{Ce}-\mathrm{TiO}_{2}>\mathrm{Ag}-\mathrm{TiO}_{2}>\mathrm{TiO}_{2}$ (Liang, Li, and Jin 2012). The reason for increasing photocatalytic oxidation due to doping is increase of chemisorbed oxygen at the surface of $\mathrm{TiO}_{2}$ (Yang et al. 2006). It creates an imbalance charge vacancy on the catalyst surface.

\subsubsection{Visible light responsive photocatalysts}

Since UV sources are power consuming, costly, and hazardous to health, visible sources are readily available, inexpensive and energy saving. To enhance the spectrum, range of photocatalyst from UV light to visible light; three methods have been used: transition metal doping into $\mathrm{TiO}_{2}$; doping of nitrogen into $\mathrm{TiO}_{2}$ and with sensitizing dyes. Transition metal ions like $\mathrm{Mn}, \mathrm{Fe}, \mathrm{V}, \mathrm{Cr}, \mathrm{Co}, \mathrm{Ni}$ or $\mathrm{Cu}$ increases the spectrum region into the visible light region (Zang et al. 2000). Presence of metals like $\mathrm{Li}^{+}, \mathrm{Ce}^{3+}, \mathrm{Co}^{3+}$, $\mathrm{Zn}^{2+}, \mathrm{Cd}^{2+}, \mathrm{Cr}^{3+}, \mathrm{Fe}^{3+}, \mathrm{Al}^{3+}, \mathrm{Mn}^{2+}$, and Pt sufficiently change the photocatalytic activity of $\mathrm{TiO}_{2}$. Different nitrogen-doped $\mathrm{TiO}_{2}$ were used as photodegradation of gaseous HCHO (Zang et al. 2000). In the case of visible light irradiation $\mathrm{TiO}_{2-X} \mathrm{~N}_{X}$ has better photocatalytic activity than $\mathrm{TiO}_{2}$. The addition of $\mathrm{ZrO}_{2}$ intoTiO ${ }_{2-X} \mathrm{~N}_{X}$ possesses higher porosity, higher surface area, and enhanced thermal stability rather than $\mathrm{TiO}_{2-X} \mathrm{~N}_{X}$ samples (Wang et al. 2006).

A very few literatures have quoted the effect of noble metal on photocatalyst. Noble metal doping into $\mathrm{TiO}_{2}$ has a higher capability to transfer electrons. In the case of $\mathrm{Pt}-\mathrm{TiO}_{2}$, Pt plays the role of core of core-shell Pt-TiO ${ }_{2}$ which can increase the photo-activity for abatement of HCHO (Zhu and $\mathrm{Wu}$ 2015). To enhance the spectrum, range of photocatalyst from UV to visible range, gold $(\mathrm{Au})$ 
nanoparticle support was used on $\mathrm{TiO}_{2}$ because of its high visible light absorption (Tsukamoto et al. 2012; Wang and Astruc 2014; Yang et al. 2014). The preparation of Au nanocatalyst affects the catalytic activity process. Atmospheric pressure oxygen has strong activity for $\mathrm{CO}$ oxidation which activates the $\mathrm{Au} / \mathrm{TiO}_{2}$ nanocatalyst (Zhang et al. 2015a).

There is some literature available on silver ion $\left(\mathrm{Ag}^{+}\right)$( $\mathrm{Liu}$ et al. 2003; Venkataraj et al. 2002) which suppressed the recombination of charge at the surface of $\mathrm{TiO}_{2}$. Doping of silver into $\mathrm{TiO}_{2}$ reduces the anatase growth rate which ultimately results in low crystallinity of anatase structure with comparison to pure $\mathrm{TiO}_{2}$, the crystallite size of Ag-doped $\mathrm{TiO}_{2}$ decreases. $\mathrm{TiO}_{2}$ - $\mathrm{Ag}$ and $\mathrm{TiO}_{2}$-Ag-TEA permit higher degradation rates as compared to pure $\mathrm{TiO}_{2}$ (Kocareva, Grozdanov, and Pejova 2001). The different state of silver $\mathrm{Ag}^{+}, \mathrm{Ag}^{0}$, and metal $\mathrm{Ag}$ at the surface of $\mathrm{TiO}_{2}$ suppresses the recombination of electron-hole which leads to an increase the photocatalytic activity of $\mathrm{TiO}_{2}$ (Ubolchonlakate, Sikong, and Tontai 2010). The mechanism involves;

$$
2 \mathrm{Ag}^{+}+\mathrm{HCHO}+3 \mathrm{OH}^{-} \rightarrow 2 \mathrm{Ag}+\mathrm{HCOO}^{-}+2 \mathrm{H}_{2} \mathrm{O}
$$

HCHO degradation by $\mathrm{TiO}_{2}$ or $\mathrm{TiO}_{2}$ composite can be written as:

$$
\begin{gathered}
\mathrm{HCHO}+\mathrm{OH}^{*} \rightarrow \mathrm{HCO}^{*}+\mathrm{H}_{2} \mathrm{O} \\
\mathrm{HCO}^{*}+\mathrm{OH}^{*} \rightarrow \mathrm{HCOOH} \\
\mathrm{HCOOH}+2 h^{+} \rightarrow \mathrm{CO}_{2}+2 \mathrm{H}^{+}
\end{gathered}
$$

Metal and non-metal doping are suitable techniques for improving the photo-activity of Titania. Doping metal atoms depressed the recombination of electrons and holes while doping nonmetal atoms can generally influence the different properties of titania such as lattice structure, band gap (Asahi et al. 2001; Khan, Al-Shahry, and Ingler 2002; Lin et al. 2007; Ohno et al. 2004). Photocatalyst doped with silver ion has been developed by Vohra et al. (2006) to devastate the airborne microbes. The result shows that photocatalyst doped with $\mathrm{Ag}$ can be used effectively for high concentrated contaminants. Zhao et al. (2004) have quoted that spectrum region and photocatalytic activity can be improved by doping with non-metal boron and metal oxide $\mathrm{Ni}_{2} \mathrm{O}_{3}$. Zhang et al. (Liu et al. 2008) have reported that strong absorption in the visible range for nitrogen nickel doped Titania. Absorption line is moved to lower energy region for the different proportion of nitrogen nickel doped titania such as $\mathrm{N}(0.010) \mathrm{Ni}(0.015) \mathrm{TiO}_{2}(600)$, while no absorption for samples $\mathrm{Ni}(0.015) \mathrm{TiO}_{2}(600)$ and pure $\mathrm{TiO}_{2}(600)$ have observed. The bandgap energies were 2.29, 2.30, 3.17 and $3.15 \mathrm{ev}$ have been reported for sample
$\mathrm{N}(0.010) \mathrm{Ni}(0.015) \mathrm{TiO}_{2}(600), \mathrm{N}(0.010) \mathrm{TiO}_{2}(600)$, pure $\mathrm{TiO}_{2}(600)$ and $\mathrm{Ni}(0.015) \mathrm{TiO}_{2}(600)$.

It shows the decrease in the bandgap due to the mixing of nitrogen. Transition metal ions doping in $\mathrm{TiO}_{2}$ inject high energy ions into the $\mathrm{TiO}_{2}$ lattice during ion implantation techniques. Anpo, Tanahashi, and Kubokawa (1980), Anpo et al. (1985, 2000), Yamashita et al. (1998) have experimented with the transition metal doping like $\mathrm{V}, \mathrm{Cr}$, and $\mathrm{Fe}$ on $\mathrm{TiO}_{2}$. Lam et al. (2007) has reported that in absence of $\mathrm{Cr}$ ion; even $1.2 \mathrm{~mW} / \mathrm{cm}^{2}$ visible intensity light could not activate the photo-activity of $\mathrm{TiO}_{2}$. After injection of $\mathrm{Cr}$ ion $\mathrm{Cr} / \mathrm{TiO}_{2}$ thin film gets activated for visible light. Heterostructured combination of waste zeolite and graphitic carbon nitride supported on $\mathrm{TiO}_{2}$ has prepared by Liu and Lin (2019) under the market available LED light for diminishment of HCHO. The decomposition of formaldehyde in the range of UV and visible light at different wavelengths is given in Table 1.

\subsection{Kinetics and mechanism involved}

For progression of the photocatalysis, generally initial steps are as below:

$$
\begin{gathered}
\mathrm{TiO}_{2}+h v \rightarrow \text { holes }+ \text { electrons } \\
\text { holes }+\mathrm{OH}^{-} \rightarrow \cdot \mathrm{OH} \\
\mathrm{Ti}^{4+}+e^{-} \rightarrow \mathrm{Ti}^{3+} \\
\mathrm{Ti}^{3+}+\mathrm{O}_{\text {2ads }} \rightarrow \mathrm{Ti}^{4+}+O_{\text {2ads }}^{-} \\
\mathrm{OH}^{\cdot}+\text { pollutant } \rightarrow \text { oxidized polltant }
\end{gathered}
$$

The absorbed formaldehyde on the surface of catalyst will be oxidized by hydroxyl radicals and superoxide ions which are also termed as highly reactive components. During this process some byproducts would also have formed which will be converted in $\mathrm{CO}_{2}$ by $\mathrm{O}_{2}^{\bullet}$ or $\mathrm{O}^{\bullet}$ oxidation. Photo-degradation process for formaldehyde in the steps of oxidation and reduction can be inscribed as follows (Ding et al. 2006):

$$
\mathrm{TiO}_{2} \rightarrow{ }^{\text {photon }} \text { electrons }+ \text { holes }
$$

Oxidation

$$
\begin{gathered}
\mathrm{HCHO}+\mathrm{H}_{2} \mathrm{O}+2 h^{+} \rightarrow \mathrm{HCOOH}+2 \mathrm{H}^{+} \\
\mathrm{HCOOH}+2 h^{+} \rightarrow \mathrm{CO}_{2}+2 \mathrm{H}^{+} \\
\text {Reduction } \mathrm{O}_{2}+4 e^{-}+4 \mathrm{H}^{+} \rightarrow \mathrm{H}_{2} \mathrm{O}
\end{gathered}
$$




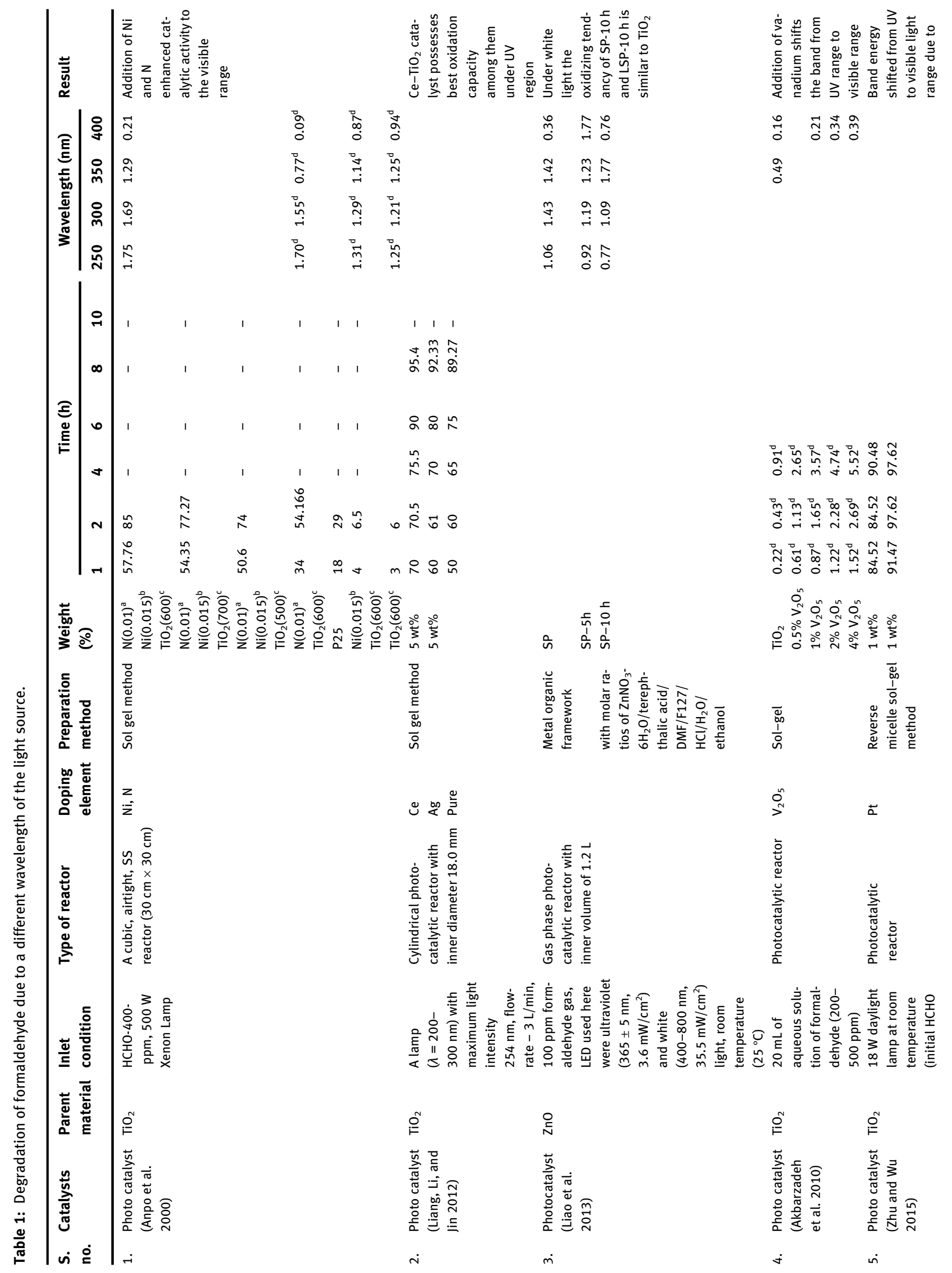




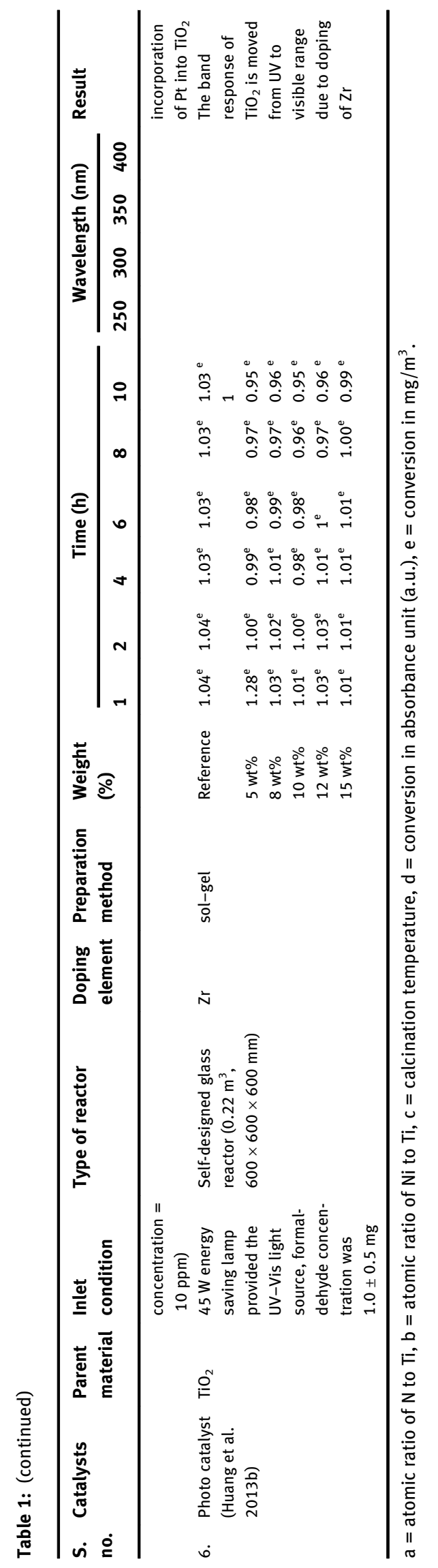


The above reactions illustrated that four $\mathrm{h}^{+}$is stoichiometrically required for complete oxidation of one $\mathrm{HCHO}$ molecule.

\subsection{Kinetic experiments of photocatalytic oxidation}

Extracting data from kinetic experiments is the prime factor for the optimum design of the reactor. An ample number of the test has been performed by Goswami, Trivedi, and Block (1997) by changing the influencing parameters like water vapor content, the intensity of light, air velocity, etc. over the $\mathrm{TiO}_{2}$ photocatalyst for varying the reaction timing for the destruction of contaminants.

\subsubsection{Light sources and intensity}

In photocatalytic process recombination electron-hole pair and interstitial charge transfers are second-order and first-order processes respectively which show that while increasing the light intensity rate of recombination of electron and holes increases which ultimately lower the quantum efficiency (Yang and Liu 2007). By literature it has been noted that reaction rate is directly proportional to light intensity for the low intensity of light and is however proportional to the square root of intensity of light under medium light intensity and totally independent of light intensity under high light intensity.

\subsubsection{Effect of water vapor}

Total photocatalytic decomposition of formaldehyde into $\mathrm{CO}_{2}$ gets decreased due to the insufficient water vapor. 50\% relative humidity along with sufficient stay time creates an efficient quantity of water molecules to cause inactivation of microorganisms (Goswami 1998). On the other hand, on surface of catalyst, the presence of excess water vapor can also reduce the reaction rate because excess water vapor can block active sites on the surface. The effect of water vapor on formaldehyde oxidation can analyze as: with an increase of water vapor from low to high, the oxidation rate will also increase proportionally but after that as water vapor will cross the optimum level the reaction rate immediately start decreasing. For the below, $10 \mathrm{ppmv}$ concentration of formaldehyde with relative humidity ranges between 15 and 60\% Langmuir-Hinshelwood suggests 1st order oxidation rate for formaldehyde (Zhao and Yang 2003). Up to 35\% RH the decomposition of formaldehyde into $\mathrm{CO}_{2}$ increases after that it will start diminishing hence 35\% RH turns to be the optimal condition for degradation rate (Liang, Li, and Jin 2012).

In existence of water vapor, the increased reaction rate is observed due to the behavior of hydroxyl radicals as a hole trap to create surface occupied hydroxyl radicals. During photocatalysis hydroxyl radicals carried out two action, one is capturing of $\mathrm{HCHO}$ molecules and the second one is reducing the electron-hole recombination (Liang, $\mathrm{Li}$, and Jin 2012).

\subsubsection{Contaminant concentration}

The concentration of reactants may also have an impact on the reaction rate similar to light intensity and relative humidity. Different reactant proportion alters the reaction rates. As per Noguchi et al. (1998), HCHO concentration above the 600 ppmv reduces reaction rates. Deng et al. (2017) have also given the range of initial concentration to determine the order of the reaction. According to him HCHO ranging from 35 to $107 \mathrm{ppm}$ does not affect the conversion of formaldehyde. Langmuir-Hinshelwood model directly relates between contaminant concentration and reaction rates. Generally, the actual concentration of VOCs is lesser in normal indoor but for the investigation of the oxidation process, there is a need for higher concentration.

\subsubsection{Photocatalytic reactors}

Basically the surface of reactors layered with catalyst is used to degrade the VOCs. Flat plate and annular reactor are the basic structure for the evaluation of kinetic models. Other than this, for achieving greater surface area different models are design which ultimately improves performance and provide better radiation on catalyst surface. Commercially available examples are: monolith, packed bed and fluidized bed photo catalytic reactors. With some improvisation for increasing the catalyst area other reactors are corrugated plate (Passalía, Alfano, and Brandi 2012), multi plate, multi annular (Zazueta, Destaillats, and Puma 2013), foam packed bed (Ibhadon et al. 2007) and paper based immobilized $\mathrm{TiO}_{2}$ reactors (Adjimi et al. 2014).

For greater air inlet, plate type and annular type reactors were not commercially appropriate. Though these types' reactors are only used for investigating different kinetic parameters. For appropriate design and greater conversion over unit mass of catalyst, packed bed reactors are usually available. This reactor also has the limitation of unit maintenance. For overcoming this fluidized bed reactors are the option with low pressure drop. Monolith reactors possess increased flow, low pressure drop and 
compact design. This has also limitation of quick diminishment of light intensity. This limitation can overcome with improvisation of optical fibers passing with each monolith (Boyjoo et al. 2017).

To overcome the different drawback of photo catalytic reactors several improvements have been done to increase the efficiency. For example: Qin et al. (2020) has used annular reactor to provide uniform illumination of catalyst and increased flux flow of the contaminants. This modified photocatlytic reactor is widely used in practical use. They have concluded that degradation efficiency of HCHO with foil catalyst annular photo reactor was 2.28 times greater than commercial $\mathrm{TiO}_{2}$ powder catalysts.

\section{Catalytic oxidation}

Due to the formation of harmless $\mathrm{CO}_{2}$ and $\mathrm{H}_{2} \mathrm{O}$ through highly effective total degradation of $\mathrm{HCHO}$, photocatalytic oxidation was a demanding option for complete catalytic oxidation of $\mathrm{HCHO}$. Various by-products which are harmful in nature like $\mathrm{CO}$ were found in the degradation of $\mathrm{HCHO}$ (Yang et al. 2007). Another disadvantage that makes PCO insufficient is that catalytic surface gets deactivated by time. Moreover, a catalyst possesses high reactivity with the confirmation of restricted energy requirement for the process of catalytic oxidation. At an increased temperature i.e. thermal or at room temperature i.e. non-thermal, catalytic oxidation uses a catalyst for diminishment of VOCs. Hence, at ambient temperature catalytic oxidation possess assuring option for diminishment of VOCs emission since it converts VOCs into $\mathrm{CO}_{2}$ (Zhang, Jiang, and Shangguan 2016). Catalytic oxidation also termed as a low temperature (293-673 K) degradation process and it is termed as powerful post remedial technology.

The major advantage of catalytic oxidation includes the formation of $\mathrm{CO}_{2}$ and $\mathrm{H}_{2} \mathrm{O}$ from $\mathrm{HCHO}$ with no intermediate pollutants (Bai, Arandiyan, and Li 2013; Pei and Zhang 2011). General catalysts in catalytic oxidation process increase the chemical reaction by providing sufficient activation energy $\left(E_{\mathrm{a}}\right)$ which is shown in Figure 3. Transition metal oxides (Co, $\mathrm{Ag}, \mathrm{Ni}$, and $\mathrm{Mn}$ ) (Chen et al. 2009; Imamura et al. 1994; Ma et al. 2014; Tang et al. 2006b; Wen et al. 2009; $\mathrm{Xu}$ et al. 2011) and supported noble metal (Pd, $\mathrm{Rh}, \mathrm{Pt}$ and $\mathrm{Au}$ ) (Arzamendi et al. 2009; Huang and Leung 2011a; Imamura et al. 1991; Kim, Park, and Hong 2011; Li et al. 2011; Sekine 2002; Zhang and He 2007; Zhang, He, and Tanaka 2005; Zhang, He, and Tanaka 2006; Zhang et al. 2012) catalysts are the established catalysts for the HCHO degradation at room temperature.

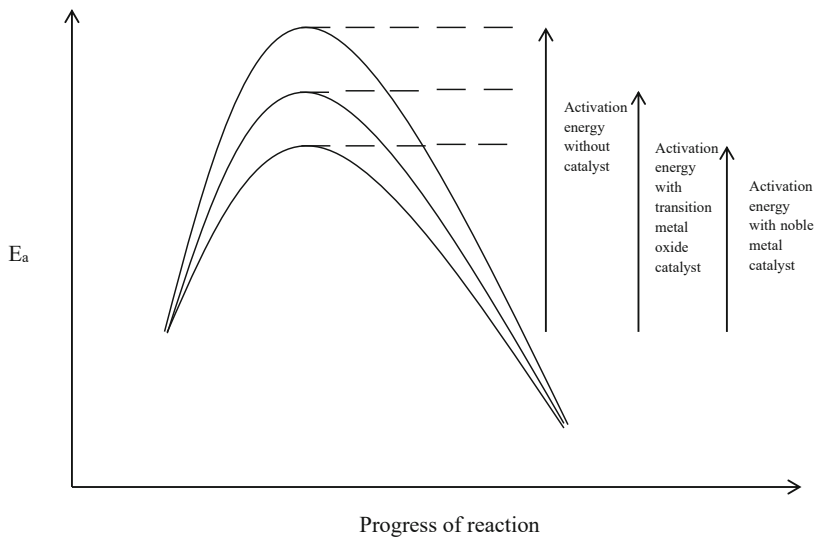

Figure 3: Requirement of energy with different catalyst.

\subsection{Noble metal catalysts}

For degradation of HCHO, noble metals support effect the catalytic activity strongly. Many researchers have been proposed in support $\mathrm{Pt}, \mathrm{Pd}, \mathrm{Au}$, Rh which is having strong catalytic activity and stability. Complete oxidation of formaldehyde can be achieved through noble metal. In Figure 1, it has been shown that activation energy requirement after noble support gets decreased and ambient temperature is sufficient for oxidation of HCHO. Among all noble metal catalysts, Pt support affects strongly and it is sufficient to do oxidation at ambient temperature. Generation of $\mathrm{CO}_{2}$ and $\mathrm{H}_{2} \mathrm{O}$ on noble doped supports is shown in Figure 4.

\subsubsection{Pt supported noble metal catalyst}

Platinum has a very high dispersion degree over $\mathrm{TiO}_{2}$ (Zhang, He, and Tanaka 2005). Zhang, He, and Tanaka (2005) have reported that $\mathrm{Pt} / \mathrm{TiO}_{2}$ catalyst has a $100 \%$ conversion of HCHO. Peng and Wang (2007) has reported that at $20^{\circ} \mathrm{C} \mathrm{HCHO}$ conversion was only $14.3 \%$ but at $120^{\circ} \mathrm{C}$ the conversion becomes $97 \%$ even at $1 \% \mathrm{Pt}$ loaded $\mathrm{TiO}_{2}$. The optimized use of $\mathrm{Pt}$ is a great concern till now since it is

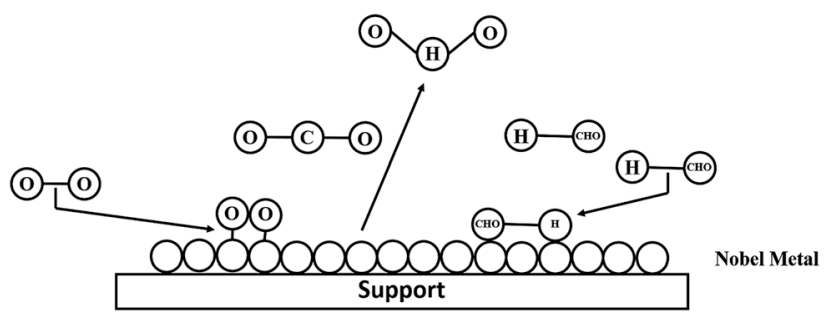

Figure 4: Formaldehyde conversion in $\mathrm{CO}_{2}$ and $\mathrm{H}_{2} \mathrm{O}$ on noble metal doping. 
highly expensive from other catalysts. A very low concentration of $\mathrm{Pt}$ even at $0.1 \mathrm{wt} \%$ at $\mathrm{TiO}_{2}$ possesses excellent conversion of $\mathrm{HCHO}$ at ambient temperature (Huang and Leung 2011b).

A comparative catalytic activity has been shown with taking pure $\mathrm{TiO}_{2}$ and $\mathrm{Pt}-\mathrm{TiO}_{2}$ is given in Table 2. The removal efficiency has been remarkably increased by using such catalyst. With the various pre-treatment of Pt, the valence state of Pt can be changed which ultimately influenced the $\mathrm{HCHO}$ removal efficiency (An et al. 2013). $\mathrm{MnO}_{2}$ have better catalytic efficiency rather than other transition metal oxide. $\mathrm{Yu}$ et al. (2011) has made catalyst $\mathrm{Pt} / \mathrm{MnO}_{2}$ to test their performance. They reported that catalytic activity of Pt loading on urchin (support) like $\mathrm{MnO}_{2}$ vary in a fashion of $2 \mathrm{wt} \% \mathrm{Pt} /$ urchin like $\mathrm{MnO}_{2}>1 \mathrm{wt} \% \mathrm{Pt} /$ urchin-like $\mathrm{MnO}_{2}>$ urchin-like $\mathrm{MnO}_{2}$. Preparation through colloidal deposition route $\mathrm{Pt}$ supported iron oxide $\left(\mathrm{Pt} / \mathrm{Fe}_{2} \mathrm{O}_{3}\right)$ showed excellent catalytic activity and long duration stability over $\mathrm{HCHO}$ oxidation (An et al. 2011). An et al. (2013) has prepared $\mathrm{Pt} / \mathrm{Fe}_{2} \mathrm{O}_{3}$ catalyst with several methods like co-precipitation, impregnation, and colloidal-deposition method. They found out that relatively higher catalytic activity for the colloidal deposition method $\left(\mathrm{Pt} / \mathrm{Fe}_{2} \mathrm{O}_{3}-\mathrm{CD}\right)$ among different methods used. Due to its high dispersion degree, $\mathrm{Pt}$ could weaken the $\mathrm{Fe}-\mathrm{O}$ bond presented at the $\mathrm{Pt} / \mathrm{FeO}_{x}$ interstitial and ultimately fasten the active oxygen HCHO oxidation. Extremely low Pt content was proved to be the dominant for catalytic oxidation of $\mathrm{HCHO}$ at ambient temperature, although practical aspect of this type of catalyst diminishes with the period of time i.e. not active.

Alkali metal ions (like $\mathrm{Li}^{+}, \mathrm{K}^{+}$and $\mathrm{Na}^{+}$) have strong stabilization ability. Pt-O $(\mathrm{OH})_{x}$-alkali-metal species have stabilized atomic dispersion on the surface of the catalyst and it became an efficient low surface catalyst. Zhang et al. (2012) have shown a low-temperature catalyst $z \% \mathrm{Na}-1 \%$ $\mathrm{Pt} / \mathrm{TiO}_{2}$ with varying loadings of $\mathrm{Na}(z=0,1,2)$ at a gas hourly space velocity (GHSV) of $12,000 \mathrm{~h}^{-1}$. They found out that $\mathrm{HCHO}$ completely conversed at $15^{\circ} \mathrm{C}$ while in the case of $1 \% \mathrm{Na}$ and $0 \% \mathrm{Na}$ addition the conversion was 96 and $19 \%$ at the same temperature respectively. Without Pt, Na can be washed out from $\mathrm{TiO}_{2}$ surface hence Pt only can have stabilized it on $\mathrm{TiO}_{2}$. These results can also be reported for $\mathrm{Pt} / \mathrm{SiO}_{2}$ with the addition of alkali ions (Zhai et al. 2010). Due to formation of Pt- $(\mathrm{ONa})_{x}$ species, Pt species doped by Na were oxidized more as compared to $\mathrm{Pt} / \mathrm{TiO}_{2}(\mathrm{Li}$ et al. 2011; Peng and Wang 2007). The result proposed by Zhang, He, and Tanaka (2005) shows that the particle size of Pt is affected by the addition of Na as 10 (Na free), 4.8 (2\% $\mathrm{Na})$ and $6.8 \AA(1 \% \mathrm{Na})$. Addition of alkali metal ion can suppress the Pt-Pt bond in presence of $\mathrm{O}_{2}$ and deepens atomically dispersed $\mathrm{Pt}-\mathrm{O}$ species on $\mathrm{TiO}_{2}$ surface. Most of the work has been proposed on the support of $\mathrm{TiO}_{2}$ (An et al.
2013; Huang and Leung 2011a, 2011b; Li et al. 2011; Nie et al. 2013; Yu et al. 2011; Zhai et al. 2010; Zhang et al. 2012; Zhu et al. 2011). Different positive influence of alkali metal on Pt/ $\mathrm{MnO}_{2}$ has been analyzed by Chen et al. (2014). To increase the catalytic activity of birnessite and cryptomelane by noble metal support, various studies have been done till now (Liu et al. 2012a; Yu et al. 2011). Chen et al. (2014) has investigated the effect of salts $\left(\mathrm{Na}_{2} \mathrm{CO}_{3}, \mathrm{Na}_{2} \mathrm{SO}_{4}\right.$, and $\left.\mathrm{NaNO}_{3}\right)$ over $\mathrm{Pt} / \mathrm{MnO}_{2}$ and found the increasing effect of anions in salt as the following manner: $\mathrm{CO}_{3}^{-2}>\mathrm{SO}_{4}^{-2}>\mathrm{NO}_{3}^{-}$. $\mathrm{HCHO}$ conversion at $50{ }^{\circ} \mathrm{C}$ over the $\mathrm{Na}_{2} \mathrm{CO}_{3}$ supported catalyst was found $100 \%$. Since, residual anions $\left(\mathrm{SO}_{4}^{-2}\right.$, and $\left.\mathrm{NO}_{3}^{-}\right)$were col lected on the surface of $\mathrm{Pt} / \mathrm{MnO}_{2}$ hence effective surface area gets reduced with $\mathrm{Na}_{2} \mathrm{SO}_{4}$ and $\mathrm{NaNO}_{3}$ which ultimately influence the physiochemical aspects of the catalysts (Wang et al. 2012).

The advantages with using $\mathrm{Na}_{2} \mathrm{CO}_{3}$ support is that $\mathrm{CO}_{3}^{-2}$ got burn at the higher temperature which ultimately exposed the higher specific surface area and pore volume for increasing catalytic degradation of $\mathrm{HCHO}$ oxidation. During practical uses generally all the catalysts adding noble metal which are structurally granular or powder possess great value of pressure drop. They also possess some engineering limitation like dust pollution, removal of nano catalysts with corresponding gases and so on. Hence, due to low pressure drops and forming quality, macroscopically fabricated catalysts are more considerable (Groppi and Tronconi 2005; Kołodziej and Łojewska 2005). Yu et al. (2013) has investigated the diminishment of $\mathrm{HCHO}$ over $\mathrm{Au}_{0.5} \mathrm{Pt}_{0.5} / \mathrm{MnO}_{2} /$ cotton catalyst and found that $15 \mathrm{wt} \% \mathrm{Au}_{0.5} \mathrm{Pt}_{0.5} / \mathrm{MnO}_{2} /$ cotton possess best performance among $25 \mathrm{wt} \% \mathrm{Au}_{0.5} \mathrm{Pt}_{0.5} / \mathrm{MnO}_{2} /$ cotton, $10 \mathrm{wt} \% \mathrm{Au}_{0.5} \mathrm{Pt}_{0.5} / \mathrm{MnO}_{2} /$ cotton, and $6 \mathrm{wt} \% \mathrm{Au}_{0.5} \mathrm{Pt}_{0.5} /$ $\mathrm{MnO}_{2} /$ cotton. They also reported that cotton surface has gully shape which increases the superficial area of cotton and it does not affect the decomposition of HCHO itself. Cotton fiber just promotes the adsorption of HCHO. Zhang and He (2007) has proposed a comparative data for the catalytic over $\mathrm{TiO}_{2}-$ with $1 \mathrm{wt} \%$ noble metal supports (Pt, Rh, $\mathrm{Pd}$, and $\mathrm{Au}$ ). They resulted in the catalytic activity of $\mathrm{Pt} / \mathrm{TiO}_{2}>\mathrm{Rh} / \mathrm{TiO}_{2}>\mathrm{Pd} /$ $\mathrm{TiO}_{2}>\mathrm{Au} / \mathrm{TiO}_{2}>\mathrm{TiO}_{2}$. They also found that $1 \mathrm{wt} \%$ of $\mathrm{Pt} / \mathrm{TiO}{ }_{2}$ catalyst could decompose the $\mathrm{HCHO}$ into $\mathrm{CO}_{2}$ and $\mathrm{H}_{2} \mathrm{O}$ in a GHSVs of $50,000 \mathrm{~h}^{-1}$ even at ambient temperature. So, format species are potent surface variant on the $\mathrm{Pt} / \mathrm{TiO}_{2}$ and $\mathrm{Rh} / \mathrm{TiO}_{2}$ including with absorbed $\mathrm{CO}$ variant in $\mathrm{Pt} / \mathrm{TiO}_{2}$. As in case of $\mathrm{Pd} / \mathrm{TiO}_{2}$ and $\mathrm{Au} / \mathrm{TiO}_{2}$, formation of format species and its degradation into $\mathrm{CO}$ is not influencing in nature.

\subsubsection{Pd supported noble catalysts}

Better thermal stability and comparatively low cost of Pd over precious metal catalysts (like Pt and Au dependent 


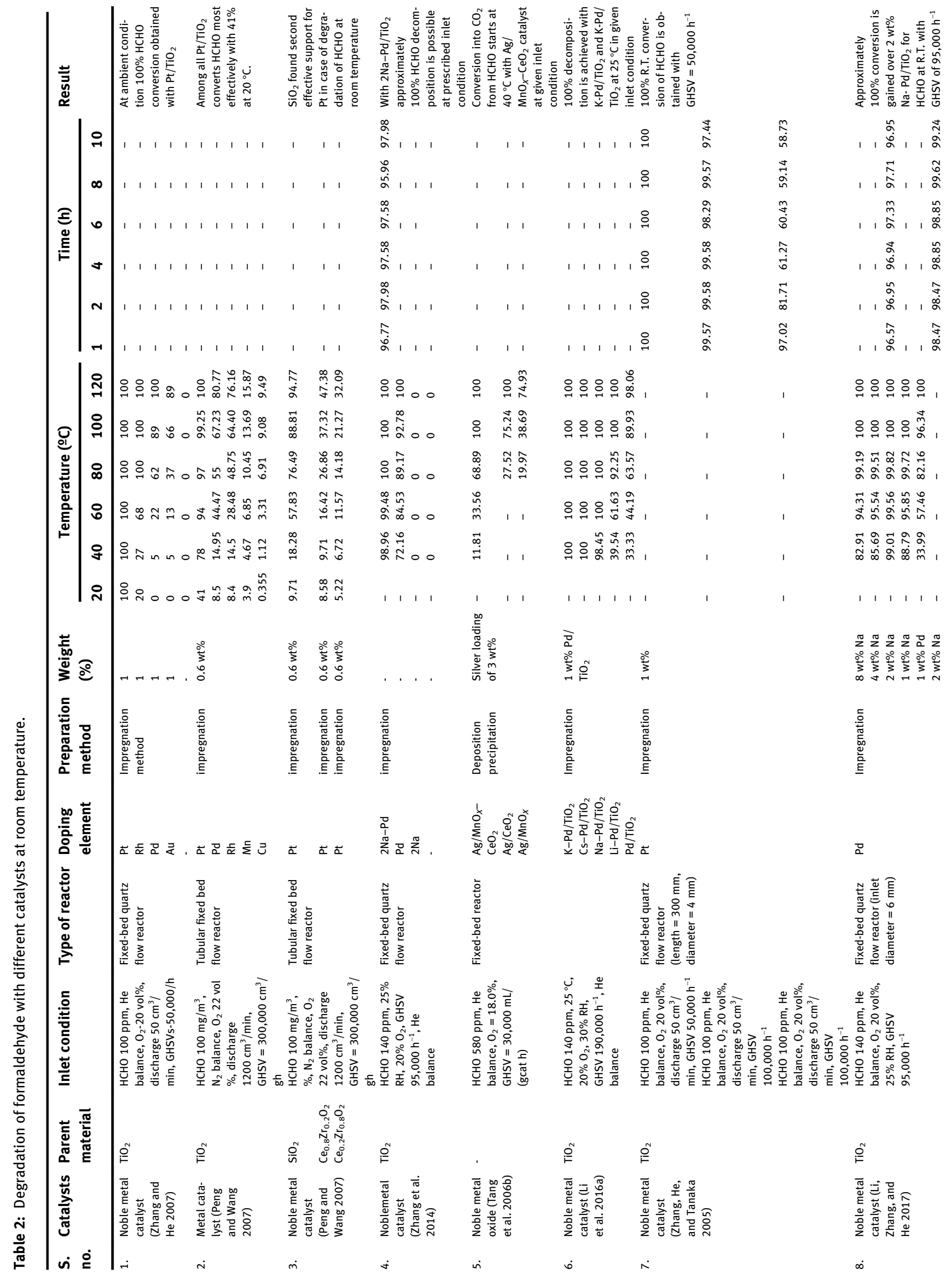




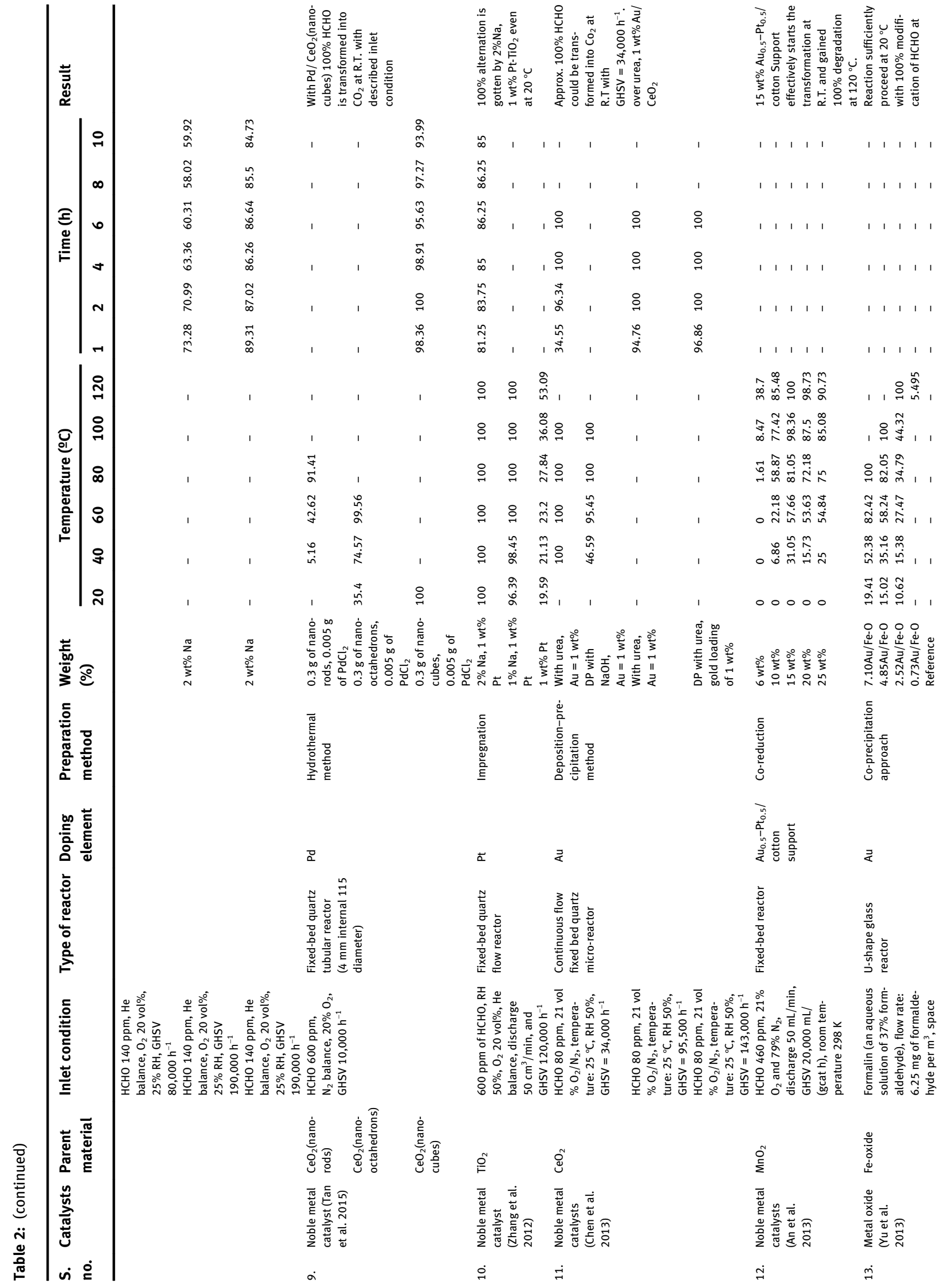




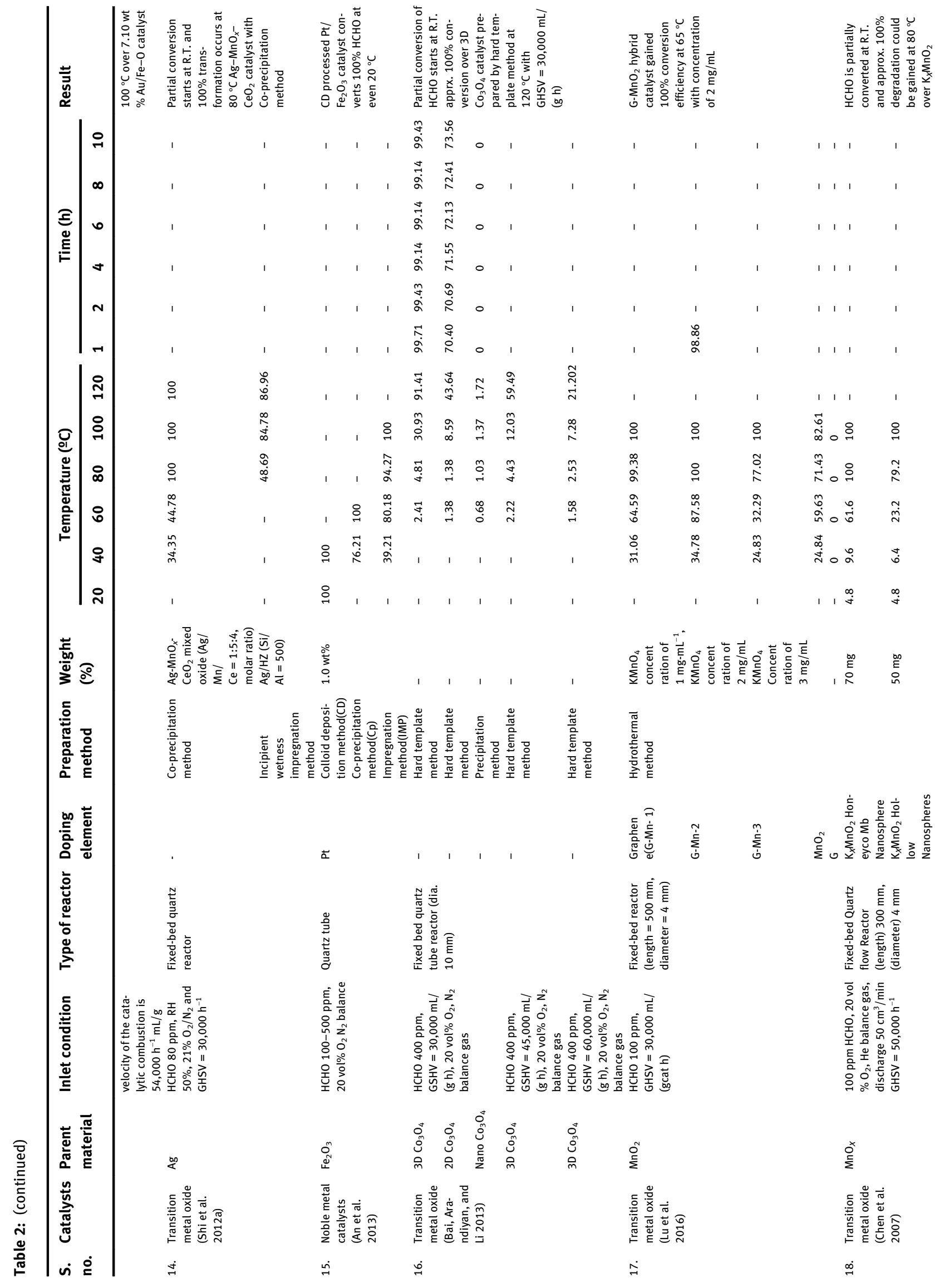




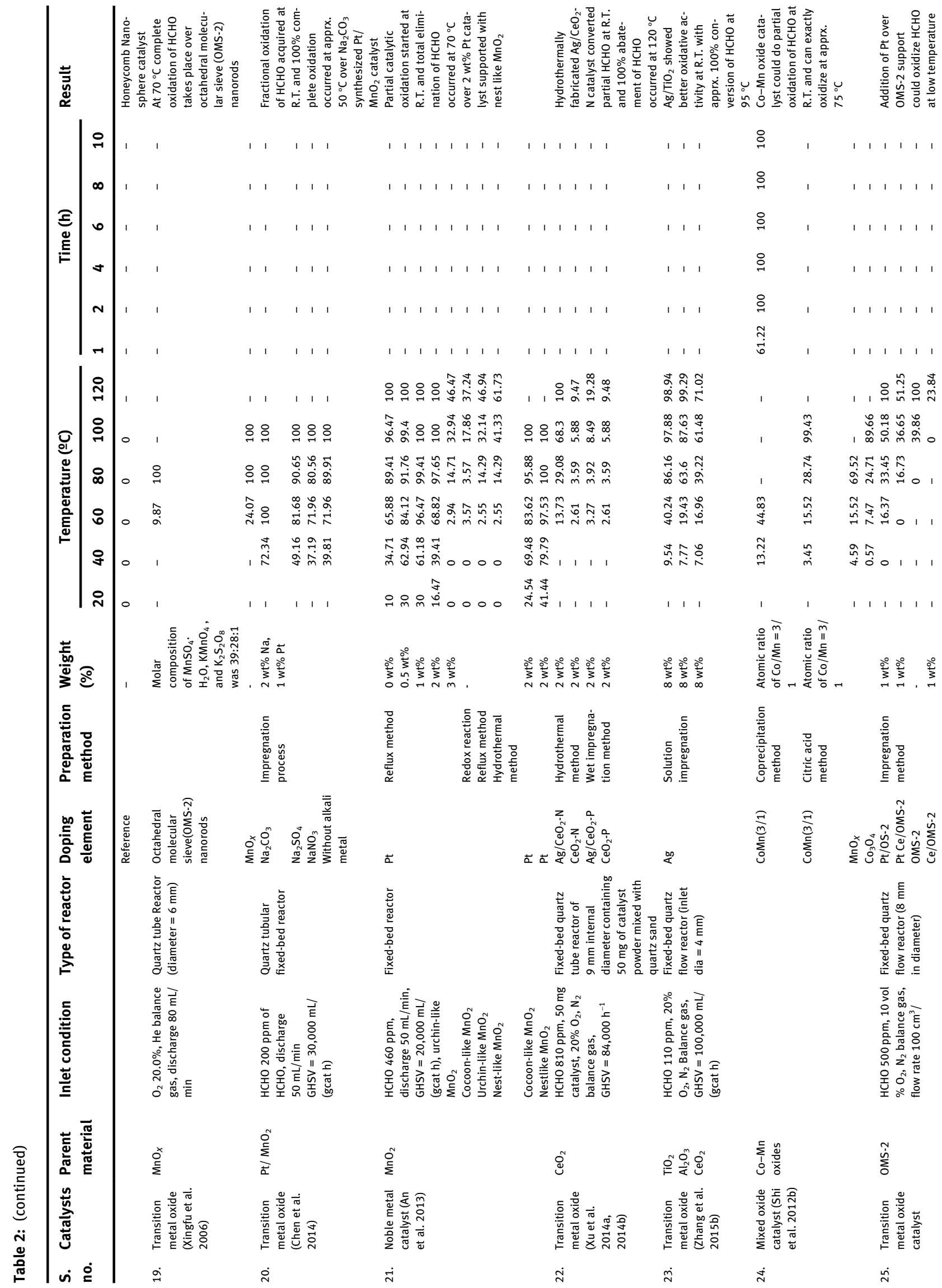




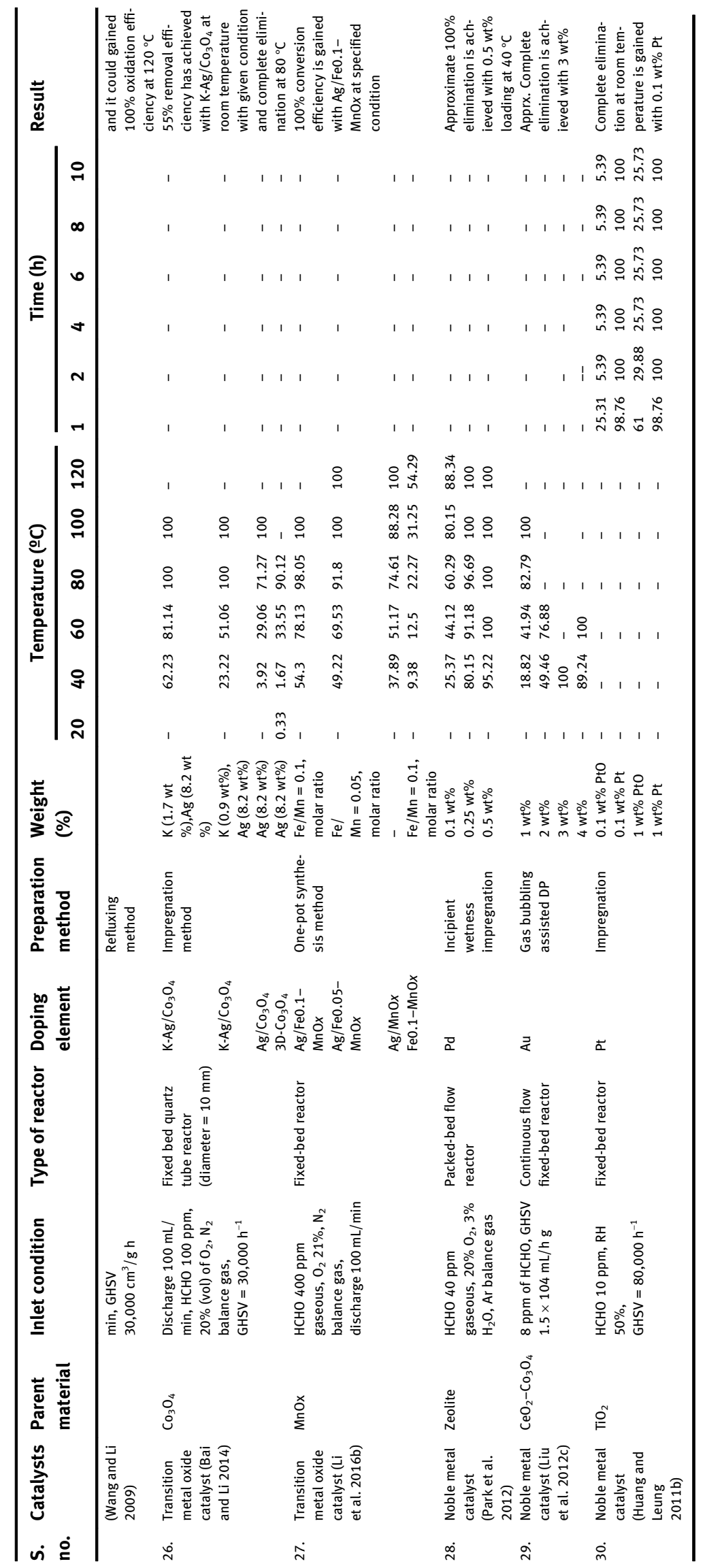


catalysts) make it beneficial of use. But it requires a high temperature for oxidation. $1 \%$ of $\mathrm{Pd}$ nanoparticles can efficiently oxidize $\mathrm{HCHO}$ at ambient temperature (Vijayakrishnan et al. 1992). Huang et al. (2013a) have also found out that the deposition precipitation method is more capricious than the impregnation method in the case of $\mathrm{Pd} /$ $\mathrm{TiO}_{2}$ catalysts due to larger capacity for production and transfer of chemisorbed oxygen. The removal efficiency of HCHO with $\mathrm{Pd} w \mathrm{t} \%$ in the case of impregnation method shows the trend in the following manner: 8.5, 93.2, and $19 \%$ removal efficiency for 0.1, 0.5, and 1\% Pd. Expensive cost of Pd limits the high Pd loading. Alkali metal as an electronic or textural conductor prefers as a catalyst for several catalytic processes including NO (Xu et al. 2014a, 2014b) and CO oxidation (Mirkelamoglu and Karakas 2006; Yentekakis et al. 1994). Zhang et al. (2014) has conducted a test on $2 \mathrm{Na}-\mathrm{Pd} / \mathrm{TiO}_{2}$ catalyst at a GHSV of $95,000 \mathrm{~h}^{-1}$. They found out that $100 \% \mathrm{HCHO}$ decomposition into $\mathrm{CO}_{2}$ and $\mathrm{H}_{2} \mathrm{O}$ at $25^{\circ} \mathrm{C}$ with a feed concentration of $140 \mathrm{ppm}$ of $\mathrm{HCHO}$. Result proves that Na species act as an inductor and stabilizer for negatively charged and well-dispersed Pd variants that promotes water and chemisorbed oxygen's activation.

A series of alkali metal (K, Li, Na and Cs) doping have investigated on $\mathrm{Pd} / \mathrm{TiO}_{2}$ support by $\mathrm{Li}$ et al. (2016b). They resulted in $\mathrm{K}>\mathrm{Cs}>\mathrm{Na}>\mathrm{Li}$ like the trend in the condition of $550 \mathrm{ppm}$ HCHO and a GHSV of $640,000 \mathrm{~h}^{-1}$ over $\mathrm{Pd} / \mathrm{TiO}_{2}$ support. The highest $\mathrm{Pd}$ dispersion degree with active sites is showing by $\mathrm{K}-\mathrm{Pd} / \mathrm{TiO}_{2}$ catalyst among all in ambient temperature HCHO oxidation. Li, Zhang, and He (2017) have reported the optimized value of loading at $\mathrm{Pd} / \mathrm{TiO}_{2}$ support is $2 \mathrm{wt} \%$ in a GHSV range of $80,000-190,000 \mathrm{~h}^{-1}$ and $\mathrm{RH}$ of $25-65 \%$. They found an activity trend of $2.0 \mathrm{Na}-$ $\mathrm{Pd} / \mathrm{TiO}_{2}>1.0 \mathrm{Na}-\mathrm{Pd} / \mathrm{TiO}_{2}>4.0 \mathrm{Na}-\mathrm{Pd} / \mathrm{TiO}_{2}>\mathrm{Pd} / \mathrm{TiO}_{2}$ among the different loadings of sodium. Galvan et al. (Huang et al. 2013b) has reported that total combustion of $\mathrm{HCHO}$ had achieved at $220^{\circ} \mathrm{C}$ temperature over $18.2 \% \mathrm{Mn} /$ $\mathrm{Al}_{2} \mathrm{O}_{3}$ catalyst. But due to the addition of $0.1 \%$ Pd this temperature gets reduced to $90{ }^{\circ} \mathrm{C}$ (Âlvarez-Galván et al. 2004). At the surface of $\mathrm{Pd}-\mathrm{Mn} / \mathrm{Al}_{2} \mathrm{O}_{3}$, several activities have involved for the decomposition of $\mathrm{HCHO}$. The relative rates are $\mathrm{PdO}>\mathrm{MnO}_{x} \gg \mathrm{Al}_{2} \mathrm{O}_{3}$. Interstitial oxygen of the $\mathrm{PdO}$ cluster has high activity in oxidation of $\mathrm{HCHO}$ (Cordi and Falconer 1996).

\subsubsection{Supported gold catalysts}

Earlier gold was assumed as the poor heterogeneous catalyst due to its electronic structure. However, after the discovery of Haruta et al. (1989), highly dispersed particles of metallic gold permit co-oxidation at relatively low temperatures. This was just the initiation of the application of gold as the catalyst. Gold catalysts have been reported as active catalysts in hydrogenation of carbon oxide, in water gas shift reaction and most importantly in oxidation of VOCs (Delannoy et al. 2010; Dobrosz-Gómez, Kocemba, and Rynkowski 2008; Hosseini et al. 2012; Wang et al. 2011; Yi et al. 2010a, 2010b). In spite of the high-temperature requirement for total oxidation of $\mathrm{HCHO}, \mathrm{Fe}_{2} \mathrm{O}_{3^{-}}, \mathrm{CeO}_{2^{-}}$, and $\mathrm{ZrO}_{2}$-supported $\mathrm{Au}$ has been proved as an active catalyst (Hong et al. 2010; Li et al. 2007). Chen et al. (2013) has prepared $\mathrm{Au} / \mathrm{TiO}_{2}$ catalyst by two methods i.e. deposition precipitation (DP) with urea and with $\mathrm{NaOH}$ to examine the catalytic activity of $\mathrm{Au} / \mathrm{TiO}_{2}$ for decomposition of $\mathrm{HCHO}$ oxidation. They reported that $\mathrm{Au} / \mathrm{CeO}_{2}$ (DPU prepared) shows higher catalytic activity than $\mathrm{Au} / \mathrm{CeO}_{2}$ (prepared through DPN) due to higher active surface oxygen variant even at high GHSV of $143,000 \mathrm{~h}^{-1}$. It has been illustrated that presence of Au weakens surface $\mathrm{Ce}-\mathrm{O}$ bond (Scire et al. 2003; Serre et al. 1993). Li et al. (2008) have prepared a series of gold /iron-oxide catalysts for the decomposition of HCHO through co-precipitation method. They critically observed the decomposition of $\mathrm{HCHO}$ by varying the $\mathrm{Au}$ loading from $0.73,2.52,4.85$ to $7.10 \mathrm{wt} \%$ on gold iron supported catalysts and found that $7.10 \mathrm{wt} \%$ of gold content showed highest catalytic activity.

They suggested that gold species exist in fractional charged gold atoms $\left(\mathrm{Au}^{\delta+}\right.$ where $\left.\delta<1\right)$ which is a transition state between cationic gold $\left(\mathrm{Au}^{+}\right)$and metallic gold. Liu et al. (2012a) have fabricated 3-D ordered macro-porous (3DOM) $\mathrm{Au} / \mathrm{CeO}_{2}$ catalyst with a different process named colloidal crystal template process joined with a precursor complexion technique. They noticed that $3 \mathrm{DOM} \mathrm{Au} / \mathrm{CeO}_{2}$ catalysts decomposes $30 \% \mathrm{HCHO}$ at ambient temperature and $100 \%$ decomposition showed at $\sim 75^{\circ} \mathrm{C}$ for $\sim 0.56 \mathrm{wt} \%$ of Au. Mutually connected spherical voids promoting the less aggregation and fine dispersion of Au nanoparticles may credit for their improved catalytic activity for the 3DOM structure of $\mathrm{Au} / \mathrm{CeO}_{2}$. Deactivation of 3DOM Au/ $\mathrm{CeO}_{2}$ catalyst happened due to formation of carbonate and hydrocarbon at eon surface of $3 \mathrm{DOM} \mathrm{Au} / \mathrm{CeO}_{2}$. For enhancement of result, another test using 3DOM Au/ $\mathrm{CeO}_{2}-\mathrm{Co}_{3} \mathrm{O}_{4}$ catalysts fabricated through precursor thermal decomposition assisted colloidal templating technique has carried out (Liu et al. 2012a). The result shows that catalyst $3 \mathrm{DOM} \mathrm{Au} / \mathrm{CeO}_{2}-\mathrm{CO}_{3} \mathrm{O}_{4}$ acquired proper 3DOM shape with adjustable pore sizes. Their phase structures, compositions, and elemental valence state on the surface can be monitored by regulating the molar ratio (Ce/Co). With the help of thermal decomposition of Ce and Co oxalate precursor, the nanowalls pore size of 3-4 nm were made in $3 \mathrm{DOM} \mathrm{Au} / \mathrm{CeO}_{2}-\mathrm{Co}_{3} \mathrm{O}_{4}$. They achieved $100 \%$ 
decomposition of $\mathrm{HCHO}$ at $\sim 39{ }^{\circ} \mathrm{C}$ for $3 \mathrm{DOM} \mathrm{Au} / \mathrm{CeO}_{2}-$ $\mathrm{Co}_{3} \mathrm{O}_{4}$ catalyst.

\subsubsection{Supported silver catalyst}

The different oxidation states of silver (Ag) permit it to use with different supports. Zhang et al. (2015b) has used different supports $\left(\mathrm{TiO}_{2}, \mathrm{Al}_{2} \mathrm{O}_{3}\right.$, and $\left.\mathrm{CeO}_{2}\right)$ for analyzing their catalytic activity doped with Ag. Results show that $\mathrm{Ag} / \mathrm{TiO}_{2}$ exhibit superior catalytic activity among them with $100 \%$ oxidation of $\mathrm{HCHO}$ at $95^{\circ} \mathrm{C}$ followed by 110 , $125^{\circ} \mathrm{C}$ by $\mathrm{Ag} / \mathrm{Al}_{2} \mathrm{O}_{3} \mathrm{Ag} / \mathrm{CeO}_{2}$ respectively. $\mathrm{TiO}_{2}, \mathrm{Al}_{2} \mathrm{O}_{3}$, and $\mathrm{CeO}_{2}$ have approximately equal activation energy but high dispersion degree of silver and size factor over supports create a difference. Tang et al. (2006a) have used the mixed oxide $\left(\mathrm{MnO}_{x}-\mathrm{CeO}_{2}\right)$ doped with $\mathrm{Ag}$ to improve catalytic activity of mixed oxides. Result shows that due to oxygen transfer mechanism $100 \%$ oxidation of $\mathrm{HCHO}$ takes place at $373 \mathrm{~K}$ over $\mathrm{Ag} / \mathrm{MnO}_{x}-\mathrm{CeO}_{2}$ catalyst. To use the silver more effectively Bai and $\mathrm{Li}$ (2014) has prepared 3D-Ag/ $\mathrm{Co}_{3} \mathrm{O}_{4}$ with addition of $\mathrm{K}^{+}$ions catalyst. Result shows that addition of $\mathrm{Ag}$ into $3 \mathrm{D}-\mathrm{Co}_{3} \mathrm{O}_{4}$ decreases the conversion temperature to $110{ }^{\circ} \mathrm{C}$ in GHSV of $30,000 \mathrm{~h}^{-1}$.

\subsection{Reaction mechanism and pathway for catalytic oxidation of formaldehyde}

A generalized reaction mechanism is not illustrated because of characteristic of $\mathrm{HCHO}$ molecule and catalyst is the factors on which the legitimacy of every mechanism depends. For $\mathrm{VOC}_{\mathrm{s}}$ oxidation, there are possibly three mechanisms i.e., Eley-Rideal, Langmuir-Hinshelwood and Mars-Van Krevelan (Liotta 2010; Ordóñez et al. 2002).

As per the $L-H$ mechanism, kinetics of reactions between the solid and gas phase can be quantitatively treated (Lam et al. 2007). According to this, the surface reaction between initial contaminants and oxidizer (absorbed molecules) is the basic process. In the $E-R$ mechanism, the gas phase absorbed particle retaliates with contaminant particles. Further, in case of the MVK mechanism, it is twostage redox reaction mechanisms that involve the oxidation and reduction of VOC particles and oxygen. The redox states of the MVK mechanism are as follows.

(a) First, catalysts will be oxidized by oxygen in gas phase to create an oxygen adsorption site $(0)$. This $(0)$ reacts with the absorbed particles or contaminants in the air.

(b) Simultaneously in the 2nd step pollutant molecules will reduce the oxidized catalyst (Ding et al. 2006).
The following are the two steps

$$
\begin{gathered}
\mathrm{O}_{2}+() \stackrel{k_{o}}{\rightarrow}\left(\mathrm{O}_{2}\right) \stackrel{(}{\rightarrow} 2(\mathrm{O}) \\
R+(\mathrm{O}) \stackrel{k_{i}}{\rightarrow} \mathrm{CO}_{2}+\mathrm{H}_{2} \mathrm{O}+()
\end{gathered}
$$

where $k_{o}$ represents as the oxygen rate constant, $k_{i}$ represents as constant for surface reaction rate, and blank symbol () depicts an oxygen adsorption site.

Generally, MVK mechanism is broadly applied for HCHO oxidation over platinum catalysts (Liu et al. 2012a). Rapid formation of format species from the oxidation of $\mathrm{HCHO}$ is a major step for conversion into $\mathrm{CO}_{2}$ and $\mathrm{H}_{2} \mathrm{O}$ is performed in two steps i.e.

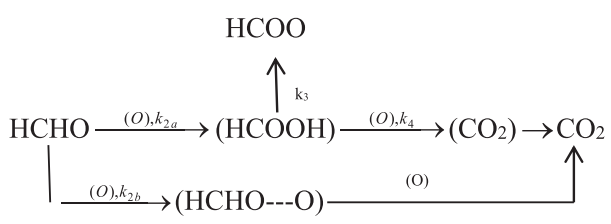

With

$$
\mathrm{O}_{2}+() \stackrel{k_{i}}{\rightarrow}\left(\mathrm{O}_{2}\right) \stackrel{()}{\rightarrow} 2(\mathrm{O})
$$

In case of $\mathrm{Pt} / \mathrm{TiO}_{2}$, at metal-support interface, after the formation of oxygen vacancies, oxygen absorbed on the active sites with packing the vacancy by oxygen molecule and coordinating with the $\mathrm{Ti}^{4+}$ as an adatom (Alexeev et al. 2005). The formation of a high intensity of oxygen species greatly influences the oxidation reaction. For sodium-free $\mathrm{Pt} / \mathrm{TiO}_{2}$ catalysts, the reaction mechanism includes the formation of formate species which is purely degraded into $\mathrm{CO}$ species (Zhang, He, and Tanaka 2006). This formed $\mathrm{CO}$ species ultimately converted into $\mathrm{CO}_{2}$ after exposure of the catalyst to $\mathrm{O}_{2}$ and finally $\mathrm{CO}_{2}$ leaves the surface. So the reaction mechanism includes the following steps for the decomposition of $\mathrm{HCHO}$ into $\mathrm{CO}_{2}$ i.e.

$$
\mathrm{HCHO} \rightarrow \mathrm{HCOO}^{-} \rightarrow \mathrm{CO} \rightarrow \mathrm{CO}_{2}
$$

In the decomposition process, rate demonstrative step is the conversion of formate into CO. Zhang et al. (2012) has studied reaction mechanism of decomposition of $\mathrm{HCHO}$ into $\mathrm{CO}_{2}$ over Sodium doped $\mathrm{Pt} / \mathrm{TiO}_{2}$ catalyst with using in situ DRIFTS. They reported that on the surface of the catalyst, two types of surface $(\mathrm{OH})$ groups were formed at 3695 and $3600 \mathrm{~cm}^{-1}$. After $60 \mathrm{~min}$, a complete reaction occurred between active $\mathrm{OH}$ groups and formate because of the disappearance of $\mathrm{HCOO}^{-}$species from the base. 
Results show a new pathway for $2 \% \mathrm{Na}-1 \% \mathrm{Pt} / \mathrm{TiO}_{2}$ catalyst i.e.

$$
\mathrm{HCHO} \rightarrow \mathrm{HCOO} \rightarrow \mathrm{OH} \rightarrow \mathrm{H}_{2} \mathrm{O}+\mathrm{CO}_{2}
$$

This reaction gives a new preferable path for the decomposition of $\mathrm{HCHO}$ into $\mathrm{CO}_{2}$ i.e. surface hydroxyls and formate reaction are preferred rather than degradation of formate into CO. Zhang, He, and Tanaka (2006) have also proposed two different paths for the decomposition process which are when deficiency of $\mathrm{OH}$ group occurs on the catalyst surface, the formation of surface $\mathrm{CO}$ starts from formate species.

$$
\mathrm{HCOO}-M \rightarrow \mathrm{OH}-M+\mathrm{CO}-M
$$

But in the case of an abundant amount of $\mathrm{OH}$ groups present, decomposition of formate into $\mathrm{CO}_{2}$ takes place.

$$
\mathrm{HCOO}-M+\mathrm{OH}-M \rightarrow \mathrm{H}_{2} \mathrm{O}+\mathrm{CO}_{2}+2 M
$$

A similar result has given by Zhang, He, and Tanaka (2006) that in case of $\mathrm{Pt} / \mathrm{TiO}_{2}$ and $\mathrm{Rh} / \mathrm{TiO}_{2}$ catalysts, effective surface species are formate species along with absorbed $\mathrm{CO}$ molecules on $\mathrm{Pt} / \mathrm{TiO}_{2}$.

$$
\mathrm{H}_{2} \mathrm{CO}_{3} \Leftrightarrow \mathrm{CO}_{2}(g)+\mathrm{H}_{2} \mathrm{O}
$$

Liu et al. (2012a) has further explained the reaction mechanism of $3 \mathrm{DOM} \mathrm{Au} / \mathrm{CeO}_{2}$ the catalyst for enhancing the catalytic oxidation of HCHO. They explained the reaction mechanism in two steps catalyzed with ionic $\mathrm{Au}^{3+}$ and metallic $\mathrm{Au}^{0}$ and suggested that higher catalytic performance has shown by ionic $\mathrm{Au}^{3+}$. Hereafter adsorption of $\mathrm{HCHO}$ takes place onto the $\mathrm{CeO}_{2}$ surface. This process includes the formation of $\mathrm{HCOOH}$ and $\mathrm{Au}^{0}$ with the transformation of active oxygen from $\mathrm{Au}_{2} \mathrm{O}_{3}$. Now formate species would be formed due to the interaction of $\mathrm{CeO}_{2}$ and $\mathrm{HCOOH} . \mathrm{CO}_{2}$ would be produced with the complete oxidation of $\mathrm{HCOOH}$. Chen et al. (2013) has elucidated the reaction intermediate using in situ DRIFTS for $\mathrm{Au} / \mathrm{CeO}_{2}$ catalysts. They also gave a similar reaction for decomposition of $\mathrm{HCHO}$ into $\mathrm{CO}_{2}$ which involves four basic steps for the decomposition. The first major step includes the formation of formate species due to oxidation of $\mathrm{HCHO}$ in the deficiency of $\mathrm{O}_{2}$ and/or $\mathrm{H}_{2} \mathrm{O}$.

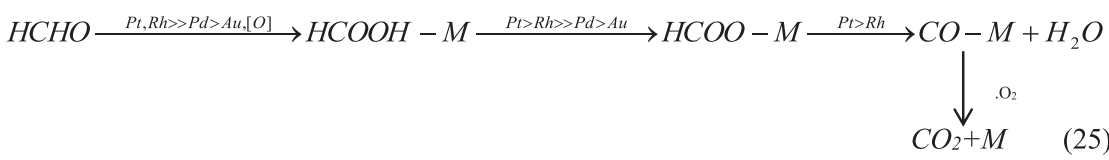

Figure 5 order of the reaction for catalytic degradation of $\mathrm{HCHO}$ on the noble metal $(\mathrm{Au}, \mathrm{Pd}, \mathrm{Rh}$, and $\mathrm{Pt}$ ) catalyst supported with $\mathrm{TiO}_{2}$.

Ma et al. (2011) has further defined the steps of catalytic reaction over $\mathrm{Au} / \mathrm{Co}_{3} \mathrm{O}_{4}-\mathrm{CeO}_{2}$ catalyst. The first step has defined for reaction is adsorption of $\mathrm{HCHO}$ on surface of $\mathrm{Co}_{3} \mathrm{O}_{4} \cdot \bullet \mathrm{CHO}$ species on surface forms due to adsorption of $\mathrm{HCHO}$.

$$
\begin{gathered}
\mathrm{Co}^{3+}+\mathrm{HCHO} \rightarrow \mathrm{Co}^{2+}+\bullet \mathrm{CHO}+\mathrm{H}^{+} \\
\bullet \mathrm{CHO}+\mathrm{O}^{*-} \rightarrow \mathrm{HCOO} \bullet \\
\mathrm{HCOO} \bullet- \\
\mathrm{Co}^{3+}+\mathrm{HCOOH} \rightarrow \mathrm{H}^{+} \rightarrow \mathrm{HCOOH} \\
\mathrm{Co}^{2+}+\mathrm{HCOO} \bullet+\mathrm{H}^{+}
\end{gathered}
$$

Now $(C-H)$ formate is attacked by active surface oxygen to form bicarbonate $\left(\mathrm{HCO}_{3}^{-}\right)$species, and this bicarbonate $\left(\mathrm{HCO}_{3}^{-}\right)$will meet with $\mathrm{H}^{+}$to form carbonic acid. $\mathrm{CO}_{2}$ will form due to dissociation of $\mathrm{H}_{2} \mathrm{CO}_{3}$ which is shown in Figure 5.

$$
\begin{gathered}
\mathrm{HCOO}^{--}+\mathrm{O}^{*-} \rightarrow \mathrm{HCO}_{3}^{-} \bullet \\
\mathrm{HCO}_{3}^{*-} \bullet+\mathrm{H}^{+} \rightarrow \mathrm{H}_{2} \mathrm{CO}_{3}
\end{gathered}
$$

$$
\mathrm{HCHO}(a d)+[0]_{S} \stackrel{k 1}{\rightarrow} \mathrm{H}^{+}+\left[\mathrm{HCOO}^{-}\right]_{S}+[]_{S}
$$

In water containing feed gas, generation of hydroxyl groups absorbed the $\mathrm{HCHO}$ and then these $\mathrm{OH}$ groups oxidize the reactant.

$$
\mathrm{HCHO}(a d)+[\mathrm{OH}]_{S} \stackrel{k_{1}^{\prime}}{\rightarrow}\left[\mathrm{HCOO}^{-}\right]_{S}+\mathrm{H}^{+}
$$

Now hereafter oxidation of equations (33) and (34) could form $\mathrm{CO}_{2}$ on $\mathrm{Au} / \mathrm{CeO}_{2}$ catalyst.

$$
\begin{gathered}
{\left[\mathrm{HCOO}^{-}\right]_{S}+\left[\mathrm{O}_{S}+\mathrm{H}^{+} \stackrel{k_{2}}{\rightarrow} \mathrm{H}_{2} \mathrm{O}+\mathrm{CO}_{2}+2[]\right.} \\
{\left[\mathrm{HCOO}^{-}\right]_{S}+[\mathrm{OH}] \stackrel{k_{2}^{\prime}}{\rightarrow} \mathrm{CO}_{2}+\mathrm{H}_{2} \mathrm{O}}
\end{gathered}
$$

Tang et al. (2006b) has investigated the catalytic oxidation of $\mathrm{HCHO}$ over $\mathrm{Ag} / \mathrm{MnO}_{x}-\mathrm{CeO}_{2}$ catalysts. For oxidation purposes, he used $\mathrm{CeO}_{2}$ which is famous for the oxygen equipped catalyst. They proposed the mechanism in a way that oxidation of $\mathrm{HCHO}$ is performed with the oxygen released due to the degradation of $\mathrm{Ag}_{2} \mathrm{O}$. Further, the formation of $\mathrm{Ag}_{2} \mathrm{O}$ is continuously achieved through the reoxidation of $\mathrm{Ag}$ from $\mathrm{MnO}_{2}$ and oxygen from $\mathrm{CeO}_{2}$ regenerate 


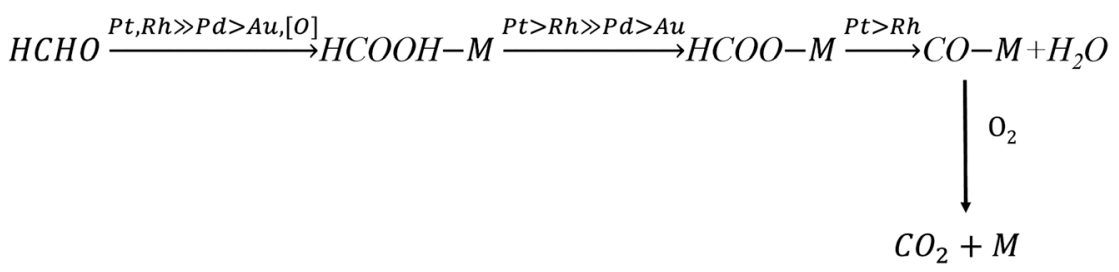

the $\mathrm{Mn}_{2} \mathrm{O}_{3}$ to $\mathrm{MnO}_{2}$. Simultaneously re-oxidation of $\mathrm{CeO}_{2}$ from $\mathrm{Ce}_{2} \mathrm{O}_{3}$ is formed through the oxygen of feed gas.

\subsection{Metal oxide catalysts used in catalytic oxidation}

After searching alternate to noble metal some metal oxide and transition metal oxides found as an active substitute (Reed and Ceder 2004). Due to different valence state and electronic configuration catalysts made through transition metal oxide possess strong catalytic activity for decomposition of volatile organic pollutants (Gluhoi, Bogdanchikova, and Nieuwenhuys 2005; Popova et al. 2010; Sinha et al. 2008; Wang and Li 2010). For VOCs oxidation, metal oxides play a strong role such as manganese, chromium, cobalt, copper, silver, iron, vanadium, and nickel. These are relatively cheaper catalysts with noble catalysts.

\subsection{1 $\mathrm{MnO}_{x}$ support}

There are generally two forms available of $\mathrm{MnO}_{x}$ i.e. cryptomelane and birnessite. It was investigated that $\mathrm{MnO}_{x}$ shows a strong influence to decompose $\mathrm{HCHO}$ at low temperatures. Crptomelane type $\mathrm{MnO}_{2}$ is chemically made of mixed-valence state of manganese $\left(\mathrm{Mn}^{4+}, \mathrm{Mn}^{3+}\right.$ and $\left.\mathrm{Mn}^{2+}\right)$ and physically composed of big open layers or channels (Villegas et al. 2005). Tang et al. (Xingfu et al. 2006) have synthesized manganese oxide octahedral molecule sieve (OMS-2) nanorods for decomposition of HCHO formaldehyde at a lower temperature. They observed that $100 \%$ conversion at $353 \mathrm{~K}$ temperature with neglecting the intermediates such as $\mathrm{CO}$ and formic acid. For $\mathrm{MnO}_{x}$ powder the temperature required for the degradation of $\mathrm{MnO}_{x}$ was found at $373 \mathrm{~K}$ which ultimately proves the morphological impact. Chen et al. (2007) has conducted a test for the decomposition of $\mathrm{HCHO}$ with monodisperse manganese oxide honeycomb and hollow nanospheres. They have compared the test result with manganese oxide octahedral molecular sieve (OMS-2) nanorod. The decreasing order of catalytic activity over HCHO decomposition as hollow $\mathrm{K}_{x} \mathrm{MnO}_{2}$ nanospheres $>$ honeycomb $\mathrm{K}_{x} \mathrm{MnO}_{2}$ nanospheres $>$ OMS-2 nanorods $>\mathrm{MnO}_{x}$ powders. Chen et al. (2009) had evaluated the complete oxidation of $\mathrm{HCHO}$ over different tunnel structure of manganese oxides which are: pyrolusite, crptomelane, and todorokite. They had shown that complete conversion of $\mathrm{HCHO}$ into $\mathrm{CO}_{2}$ and $\mathrm{H}_{2} \mathrm{O}$ can be achieved through $2 \times 2$ manganese oxide with the crystal tunnel size of $0.46 \times 0.46 \mathrm{~nm}^{2}$ at $140{ }^{\circ} \mathrm{C}$. However, the conversion is limited to 20 and $40 \%$ for $1 \times 1$ and $3 \times 3$ manganese oxide with the $0.23 \times 0.23$ and $0.69 \times 0.69$ crystal tunnel size. Tian et al. (2012) had evaluated catalytic activity of birnessite type manganese oxides prepared through the microemulsion process. They have taken BSW-100, BSW 120, and BSW-140 (manganese oxide products by heating 60, 100, 120 , and $140{ }^{\circ} \mathrm{C}$ ) catalyst to examine their catalytic properties over $\mathrm{HCHO}$ oxidation. They reported that at $100{ }^{\circ} \mathrm{C}$ BSW-120 conversion rates are about $100 \%$ which showed that BSW-120 is a better catalyst for $\mathrm{HCHO}$ decomposition. Manganese oxides reduce in the following steps:

$$
\mathrm{MnO}_{2} \rightarrow \mathrm{Mn}_{2} \mathrm{O}_{3} \rightarrow \mathrm{Mn}_{3} \mathrm{O}_{4} \rightarrow \mathrm{MnO}
$$

Jingjing et al. (Pei, Han, and Lu 2015) has prepared a hopcatile catalyst $\left(\mathrm{CuO}-\mathrm{MnO}_{2}\right)$ to examine the removal efficiency of indoor formaldehyde. They found that at room temperature $\left(25^{\circ} \mathrm{C}, 50 \% \mathrm{RH}\right.$, and $180 \mathrm{ppb}$ concentration level indoor) removal efficiency was $30 \%$ which is a quite good removal performance at room temperature. The proposed reaction process over $\mathrm{CuO} / \mathrm{MnO}_{2}$ between oxygen and formaldehyde as follows:

$$
\begin{gathered}
\mathrm{HCHO}+* \stackrel{K_{\mathrm{HCHO}}}{\longrightarrow} \mathrm{HCHO}^{*} \\
\mathrm{O}_{2}+* \stackrel{K_{\mathrm{O}_{2}}}{\longrightarrow} \mathrm{O}_{2}^{*} \\
\mathrm{HCHO}^{*}+\mathrm{O}_{2}^{*} \stackrel{K}{\longrightarrow} \mathrm{CO}_{2}^{*}+\mathrm{H}_{2} \mathrm{O}^{*} \\
\mathrm{H}_{2} \mathrm{O}^{*} \stackrel{K_{\mathrm{H}_{2} \mathrm{O}}}{\longrightarrow} \mathrm{H}_{2} \mathrm{O}+* \\
\mathrm{CO}_{2}^{*} \stackrel{K_{\mathrm{CO}_{2}}}{\longrightarrow} \mathrm{CO}_{2}+*
\end{gathered}
$$

where $K=$ reaction ppbm/s; $K_{\mathrm{HCHO}}, K_{\mathrm{H}_{2} \mathrm{O}}, K_{\mathrm{O}_{2}}$, and $K_{\mathrm{CO}_{2}}$ are the absorption equilibrium constant respectively $\mathrm{ppb}^{-1}$.

A hybrid catalyst based on graphene- $\mathrm{MnO}_{2}$ has been examined as a new catalyst for effective low-temperature oxidation of HCHO by Lu et al. (2016). This hybrid designed catalyst showed strong removal efficiency and indicating a much low $100 \%$ removal at $65^{\circ} \mathrm{C}$ temperature. They have resulted that the incorporation of graphene nanosheet exposes not only active surface but also promoted a large 

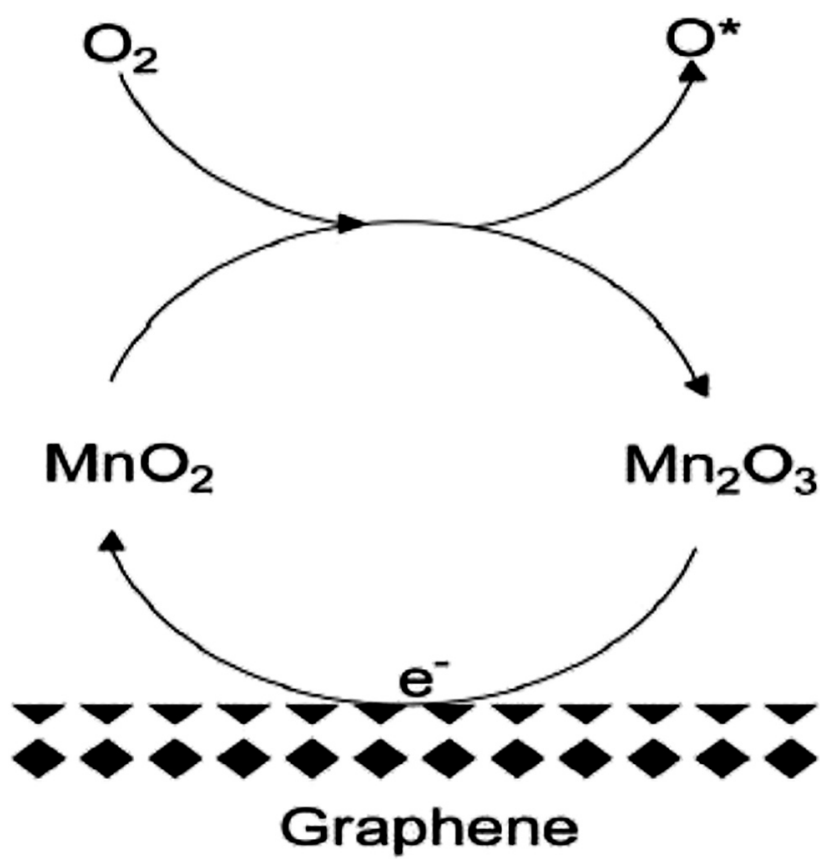

Figure 6: Oxidation of manganese oxide on graphene support (Lu et al. 2016).

amount of $\mathrm{OH}^{-1}$ surface species as given in Figure 6 ( $\mathrm{Lu}$ et al. 2016).

\subsubsection{Co oxide catalyst}

$\mathrm{Co}_{3} \mathrm{O}_{4}$ let strong catalytic performance for a different field. Bai, Arandiyan, and Li (2013) has performed a comparative study on nano- $\mathrm{Co}_{3} \mathrm{O}_{4}, 3 \mathrm{D}-\mathrm{Co}_{3} \mathrm{O}_{4}$ and $2 \mathrm{D}-\mathrm{Co}_{3} \mathrm{O}_{4}$ for catalytic oxidation of $\mathrm{HCHO}$ at $400 \mathrm{ppm} \mathrm{HCHO}$ concentration and GHSV of $30,000 \mathrm{~mL} /(\mathrm{g} \mathrm{h})$. At $130^{\circ} \mathrm{C}$ complete conversion of $\mathrm{HCHO}$ is getting through $3 \mathrm{D}-\mathrm{Co}_{3} \mathrm{O}_{4}$ in space velocity of $30,000 \mathrm{~mL} /(\mathrm{g} \mathrm{h})$ and termed as best the catalyst among all. They found that $3 \mathrm{D}-\mathrm{Co}_{3} \mathrm{O}_{4}$ has best catalytic activity among $2 \mathrm{D}-\mathrm{Co}_{3} \mathrm{O}_{4}$ and nano- $\mathrm{Co}_{3} \mathrm{O}_{4}$. They found that the stability of $\mathrm{HCHO}$ conversion is also long when tested over $160 \mathrm{~h}$. Ma et al. (2011) has evaluated the performance of $\mathrm{Co}_{3} \mathrm{O}_{4}-\mathrm{CeO}_{2}$ and $\mathrm{Au} / \mathrm{Co}_{3} \mathrm{O}_{4}-\mathrm{CeO}_{2}$ which was made through the nano casting method. The evidence of the test result clearly shows the effect of morphology. Mesoporous nanocasted $\mathrm{Co}_{3} \mathrm{O}_{4}$ catalyst yield $\mathrm{CO}_{2}$ about $20.3 \%$ at $25^{\circ} \mathrm{C}$ in contrast to $2.5 \% \mathrm{CO}_{2}$ through $\mathrm{Co}_{3} \mathrm{O}_{4}$ which were made through the precipitation method.

\subsection{3 $\mathrm{Al}_{2} \mathrm{O}_{3}$ catalyst}

Due to high surface area of $\mathrm{Al}_{2} \mathrm{O}_{3}$, Zhang and $\mathrm{He}$ (2005) have used it for catalytic oxidation of formaldehyde at room temperature. The observation shows that no catalytic oxidation of formaldehyde takes place at room temperature in $\mathrm{CO}_{2}$, but at the catalyst surface adsorption takes place. When adsorption reached to saturation point at the catalyst surface, the intensity of HCHO decreased to zero. The time of conversion of formaldehyde to $\mathrm{CO}_{2}$ decrease as 2100-700 and $400 \mathrm{~min}$ as the increase GHSV 10,00030,000 and $50,000 \mathrm{~h}^{-1}$.

\subsubsection{Mixed oxide catalyst}

Li et al. (2014) has worked on the mixed oxide catalyst and investigated the catalytic activity for $\mathrm{Mn}_{x} \mathrm{Ce}_{1-\chi} \mathrm{O}_{2}(x$ varies like 0.3, 0.5, 0.7, and 0.9) for the removal of HCHO. They prepared $\mathrm{Mn}_{x} \mathrm{Ce}_{1-x} \mathrm{O}_{2}$ with different methods (pechini) from trend and observed that for $x=0.5,100 \%$ removal efficiency has found at $270{ }^{\circ} \mathrm{C}$ for GHSV of $10,000 \mathrm{~h}^{-1}$. They arranged the result in the varying $\mathrm{Mn}$ fraction. The trend follows: T100 (100\% completion at temperature) values are 285, 270, 295, and $310{ }^{\circ} \mathrm{C}$ for $x=0.3,0.5,0.7$, and 0.9 for catalyst $\mathrm{Mn}_{x} \mathrm{Ce}_{1-x} \mathrm{O}_{2}$. The decomposition of formaldehyde due to different catalyst is given in Table 2 at room temperature.

\subsection{Operating parameter for catalytic oxidation}

For preparing strong influencing catalysts and increasing removal efficiency of $\mathrm{HCHO}$, it is important to understand significance of the operating parameter of catalytic oxidation. Catalytic activity is directly affected through operating parameter hence optimized value is mandatory.

\subsubsection{Effect of relative humidity}

Atmospheric moisture promotes catalytic activity of HCHO oxidation. This has been verified through the diffuse reflectance infrared Fourier transform (DRIFT) that presence of moisture improves performance of the hydroxyl group. There have been found some contradictory reports that indoor moisture blocks the active site by adsorbing on them at low temperatures (Skrobot et al. 2003). The un stable condition for the catalyst is arisen due to presence of $\mathrm{H}_{2} \mathrm{O}_{2}$ which helps in thorough loss of activity. In another literature, it has been found that presence of indoor moisture depreciated catalytic activity of $\mathrm{TiO}_{2}$ supported gold catalyst (Bollinger and Vannice 1996). However, Kwon et al. (2015) have reported that in presence of water vapor excellent catalytic activity have been observed with the Pt loading of more than 0.5\%. Even they reported that $100 \%$ 
conversion of $\mathrm{HCHO}$ with the $0.1 \%$ platinum concentration. In the absence of moisture, conversion decrease to $8 \%$ with $0.1 \%$ of platinum loading. The result was confirming by the DRIFTs that formation of hydroxyl group in presence of humidity improves results. This leads to the conversion of $\mathrm{HCHO}$ in formate even absence of atmospheric oxygen. Zhao et al. (2012) has investigated the impact of water vapor on reaction stability and conversion of $\mathrm{HCHO}$ into $\mathrm{CO}_{2}$ over $\mathrm{MnO}_{x}$ catalyst. Their report comes in the following form: for dryair flow approximate over $80 \% \mathrm{HCHO}$ was converted into $\mathrm{CO}_{2}$ by ozone and only $20 \%$ of $\mathrm{CO}_{2}$ comes out. But for $\mathrm{RH}=55 \%, \sim$ oxidation of $\mathrm{HCHO}$ into $\mathrm{CO}_{2}$ reported $100 \%$ with enhanced reaction stability. This conversion was supported by formation of $\mathrm{O}_{3}$ which thoroughly oxidized $\mathrm{HCHO}$ into $\mathrm{CO}_{2}$. A mechanistic study has been done by Huang et al. (2013b) for investigating the role of water vapor over $\mathrm{Pd} / \mathrm{TiO}_{2}$ catalyst. They reported that $0.1 \% \mathrm{Pd}$ made by deposition precipitation method shows strong activeness over HCHO decomposition and stable in the highly humid air. Analysis also include dissociated hydroxyl radical from water vapour support th process of adsorption and oxygen movement over the $\mathrm{Pd} / \mathrm{TiO}_{2}$ catalyst. They resulted that for $\mathrm{RH}=50 \%, 100 \% \mathrm{HCHO}$ conversion was observed while it was limited to 78.5 and $54.5 \%$ for $25 \% \mathrm{RH}$ and $0 \% \mathrm{RH}$ respectively.

\subsubsection{Effect of calcination temperature}

Calcination temperature plays an influencing role in catalytic oxidation of HCHO. Tang et al. (2006a) has synthesized $\mathrm{MnO}_{x}-\mathrm{CeO}_{2}$ catalyst at different calcinated temperature and resulted that below calcination temperature of $773 \mathrm{~K}$ due to making of $\mathrm{MnO}_{x}-\mathrm{CeO}_{2}$ solid solution. No diffraction peak related to manganese oxide has been observed and at the calcinated temperature of $773 \mathrm{~K}$ due to the phase isolation between $\mathrm{MnO}_{2}$ and $\mathrm{CeO}_{2}$, a clear diffraction peak observed for $\mathrm{MnO}_{2}$.

\subsubsection{Effect of preparation method}

Preparation of catalyst for catalytic oxidation involves different processes such as Co-precipitation, impregnation, colloidal deposition method, microemulsion, sol-gel, and modified co-precipitation. An et al. (2013) has prepared a catalyst $\mathrm{Pt} / \mathrm{Fe}_{2} \mathrm{O}_{3}$ for catalytic oxidation of $\mathrm{HCHO}$ using different methods which are co-precipitation, impregnation, and colloidal deposition methods which are listed in Table 2. Result shows that enhanced dispersion of Pt causes weakening of $\mathrm{Fe}-\mathrm{O}$ bond at interface of $\mathrm{Pt} / \mathrm{FeO}_{x}$ and hence improves the mobility of involved oxygen in oxidation of HCHO. Yu et al. (2011) have used high dispersion and small nano-sized Pt particles to improve the catalytic activity of $\mathrm{Pt} / \mathrm{MnO}_{2}$ for $\mathrm{HCHO}$ oxidation using reflux the method and hydrothermal method which is also shown in Table 2. Tang et al. (2008) has used impregnation technique for preparation $\mathrm{Pt} / \mathrm{MnO}_{x}-\mathrm{CeO}_{2}$ catalyst to decompose $\mathrm{HCHO}$ at room temperature. But An et al. (2013) has analyzed a different method to give a comparative view using co-precipitation (CP), impregnation (IMP), and colloidal deposition (CD). They resulted in higher catalytic activity for $\mathrm{CD}$ rather than $\mathrm{CP}$ and IMP method and proved through TEM result that at the surface of catalysts below $3 \mathrm{~nm}$ Pt particles were formed. Hence, it is clear that preparation method affects the structure of support and catalysts redox property. Tian et al. (2012) has used microemulsion process for birnessite type manganese oxides catalysts to increase the high surface area (upto $\left.154 \mathrm{~m}^{2} / \mathrm{g}\right)$.

\subsubsection{Effect of feed rate of $\mathrm{HCHO}$}

The performance of catalytic oxidation of $\mathrm{HCHO}$ varied with fluctuation in feed rate of $\mathrm{HCHO}$. The reaction rate of catalytic oxidation is much dependent on the molar ratio of oxygen to HCHO. Phenomena have been illustrated that lower the concentration ultimately decrease the light off temperature for catalytic oxidation of VOCs (Veser, Ziauddin, and Schmidt 1999). Peng and Wang (2007) has experiment the performance of noble metal catalyst with different feed rate of 100, 240, $400 \mathrm{mg} / \mathrm{m}^{3}$ and resulted 41.5, 33.1, and $22.7 \%$ conversion at ambient temperature for $\mathrm{HCHO}$ respectively which is described in Table 2. This result ultimately illustrated that with the decrease in feed rate of $\mathrm{HCHO}$ would increase catalytic activity at ambient temperature. Reaction rate is generally not affected through mass transfer if fast mass transfer or very slow reaction rate happened. Similar results have been also illustrated by Tang et al. (2008) that excellent HCHO decomposition is getting through low concentration of HCHO. Kim, Park, and Hong (2011) has given a similar applicability of feed rate while catalytic oxidation of HCHO. They evaluated a proper applicability of feed rate that if reaction rate will increase with increase in $\mathrm{HCHO}$ inlet feed and vice versa. The trend observed that by increasing feed concentration there is decrement in overall catalytic activity. As temperature perspective Pei, Han, and $\mathrm{Lu}$ (2015) has evaluated the feed rate for catalytic oxidation of $\mathrm{HCHO}$. They concluded that below $120^{\circ} \mathrm{C}$, decrease in conversion observed as inlet feed rate of $\mathrm{HCHO}$ increases and at $\sim 180{ }^{\circ} \mathrm{C}$ the impact of inlet concentration of $\mathrm{HCHO}$ becomes obsolete. De la Peña O'Shea et al. (2005) has used two different feeds for the simultaneous decomposition of formaldehyde and methanol and result shows that different feeds have different $100 \%$ conversion temperature. 


\subsubsection{Effect of morphology}

Morphology with exposed crystal plane on surface and crystallinity are crucial as a point of catalytic oxidation. Change in the morphology of oxide supported catalyst is in trend for regulating the catalytic activity (Feng et al. 2013; Zhou and Li 2012). Different morphology of gold doped ceria supported catalysts has been used. This involves nano-sized gold on finely defined $\mathrm{CeO}_{2}$ nanorods in which deposition of gold demonstrated to weak the $\mathrm{Ce}-\mathrm{O}$ bond by the clusters of gold. Due to creation of vacancy, $\mathrm{O}$ atom combines with $\mathrm{Au}$ atom at surface and this action would lead an electron to Ce by weaken $\mathrm{CE}-\mathrm{O}$ bond (Xu et al. 2014a, 2014b). Lie et al. (Liu et al. 2012a) have used threedimensionally averaged mesoporous $\mathrm{Au} / \mathrm{CeO}_{2}$ catalyst for improved catalysts supported by noble metal. They have observed that blockage of active sites on this structure may not happen with formed hydrocarbonate and carbonate. Hence this morphology shows efficient ways for oxidation of $\mathrm{HCHO}$. 3D macroporous $\mathrm{Au} / \mathrm{CeO}_{2}-\mathrm{Co}_{3} \mathrm{O}_{4}$ catalyst with nanoporous walls (Liu et al. 2012b). Different morphological have been also used for $\mathrm{MnO}_{2}$ for improvement in like pyrolusite, cryptomelane, and todorokite (de la Peña O'Shea et al. 2005). $\mathrm{Co}_{3} \mathrm{O}_{4}$ with 3D, 2D, and nanostructure possess a strong catalytic activity for abatement of $\mathrm{HCHO}$ (Bai, Arandiyan, and Li 2013). Su et al. (2019) have used cryptomelane type octahedral molecular sieve catalysts and investigated that degradation of $\mathrm{HCHO}$ on this morphology is greatly supported by reaction temperature from 50 to $110{ }^{\circ} \mathrm{C}$.

\subsubsection{Effect of support}

For catalytic oxidation of $\mathrm{HCHO}$ large surface area is a prime requirement but this reactivity mainly influenced active component sites. Peng and Wang (2007) has compared the different supports $\mathrm{Ce}_{0.8} \mathrm{Zr}_{0.2} \mathrm{O}_{2}, \mathrm{Ce}_{0.2} \mathrm{Zr}_{0.8} \mathrm{O}_{2}$, $\mathrm{SiO}_{2}$, and $\mathrm{TiO}_{2}$ with $0.6 \mathrm{wt} \%$ loading of $\mathrm{Pt}$ for catalytic oxidation of $\mathrm{HCHO}$ and resulted that catalytic activity of $\mathrm{TiO}_{2}$ based support is best among the $\mathrm{SiO}_{2}, \mathrm{Ce}_{0.2} \mathrm{Zr}_{0.8} \mathrm{O}_{2}$ and $\mathrm{Ce}_{0.8} \mathrm{Zr}_{0.2} \mathrm{O}_{2}$ which is shown in Table 2 also. The degradation activity belongs to the well dispersion of Pt on different types of support. At the support because of small sized Pt, has a strong effect on degradation process. For evaluating the effect of support Park et al. (2012) has used different support of $\mathrm{Mn}-\mathrm{CeO}_{2}, \mathrm{Al}_{2} \mathrm{O}_{3}$, and $\mathrm{TiO}_{2}$ with $0.25 \mathrm{Pd} / \mathrm{Beta}$ zeolite catalyst for relative study at $50,000 \mathrm{~h}^{-1}$. They resulted that $0.25 \mathrm{Pd} /$ Beta and $0.25 \mathrm{Pd} / \mathrm{Al}_{2} \mathrm{O}_{3}$ catalysts could convert over $80 \% \mathrm{HCHO}$ at $40{ }^{\circ} \mathrm{C}$ which illustrates that Beta Zeolite and $\mathrm{Al}_{2} \mathrm{O}_{3}$ come out as a strong catalyst as compare to $\mathrm{TiO}_{2}$ and $\mathrm{Mn}-\mathrm{CeO}_{2}$ for low-temperature oxidation (below $100{ }^{\circ} \mathrm{C}$ ). Yu et al. (2013) have used different support $\mathrm{MnO}_{2} /$ cotton possess strong catalytic activity for temperature below $100{ }^{\circ} \mathrm{C}$. Graphene-based $\mathrm{MnO}_{2}$ supported catalyst has been synthesized by Lu et al. (2016) and revealed that the graphene nanosheet just reduces the activation energy of $\mathrm{MnO}_{2}$ catalyst from 85.5 and $39.5 \mathrm{~kJ} / \mathrm{mol}$.

\subsubsection{Effect of metal addition to support}

To enhance catalytic oxidation of $\mathrm{HCHO}$ over catalyst and improve the reaction rate this parameter also has been taken into consideration via different researchers. For example, Zhang et al. (2012) have used alkali addition to find the stronger catalytic activity for $\mathrm{Pt} / \mathrm{TiO}_{2}$ catalyst at environment temperature and the effects are listed comprehensively in Table 2. These alkali metal ions (like $\mathrm{K}^{+}, \mathrm{Na}^{+}$, and $\mathrm{Li}^{+}$) improve stability of catalysts by atomically dispersion. With different support of $\mathrm{Pt} / \mathrm{MnO}_{2}$, Chen et al. (2014) have examined the behavior of alkali metal salts for enhanced $\mathrm{HCHO}$ oxidation. The different salt used by Chen involves $\mathrm{Na}_{2} \mathrm{CO}_{3}, \mathrm{Na}_{2} \mathrm{SO}_{4}$, and $\mathrm{NaNO}_{3}$ which resulted that at a lower temperature of $50{ }^{\circ} \mathrm{C}, 100 \%$ conversion of $\mathrm{HCHO}$ is getting through $\mathrm{Na}_{2} \mathrm{CO}_{3}$ additional catalysts. Similar tests have also been conducted on $\mathrm{Pd} / \mathrm{TiO}_{2}$ catalysts by modification of sodium by Zhang et al. (2014) with different loadings of sodium ion. They gave a comprehensive result that 2 wt $\%$ Na addition into $\mathrm{Pd} / \mathrm{TiO}_{2}$ converts $100 \% \mathrm{HCHO}$ even at room temperature of $25{ }^{\circ} \mathrm{C}$. The same results have been proposed by Li, Zhang, and $\mathrm{He}$ (2017) that due to addition $2 \mathrm{wt} \%$ Na catalytic surface produces abundant $\mathrm{OH}$ group which is ultimate increases the oxidation of $\mathrm{HCHO}$.

\section{Discussion on literature}

In this paper, the methods of catalytic activation of $\mathrm{HCHO}$ at room temperature include two processes i.e. photocatalytic process and catalytic oxidation. With all the research main focus concentrated on photocatalyst and catalytic oxidation illustrated in this point of discussion. A photocatalytic oxidation process involves different processes during the decomposition of HCHO. These are: (1) flow of HCHO to the catalyst surface; (2) soaking of reactants on the catalyst surface; (3) irradiation of photon from light intensity; (4) redox reaction on catalyst surface; (5) flow of harmless product from surface, and (6) flow of product from the catalyst surface into the air. The important process in the PCO process is the absorption of the reactant, which have to oxidize. The adsorption process is an intermediate process which occurs before the photochemical reaction to start. So, adsorption of reactant is 
important to concern while PCO. Another term that can enhance the activity of PCO is the selection of a proper reactor which extensively includes an annular reactor, monolith reactor, fluidized bed reactor, and powder plate reactor. The structures of photocatalysts also influence the PCO of HCHO. Nanoparticles with zero dimensionally have a high specific surface area, while 1D fiber tubes possess the advantage of light scattering properties. Various intermediate has also been observed during the photocatalytic oxidation of $\mathrm{HCHO}$ which are $\mathrm{HCOOH}, \mathrm{CO}$, Ozone, etc. and these species were quickly observed by catalyst surface. They would convert into $\mathrm{CO}_{2}$ otherwise they will find as the outcome. The photocatalytic performance of titania can be enhanced by addition of metal and nonmetal which suppressed recombination of electron and hole pairs. Applicability of PCO had been limited to UV activation since it extended to the visible light range $(\lambda>420 \mathrm{~nm})$ with the addition of proper doping.

There are many disadvantages of PCO listed here which are: (1) concentration of HCHO in the indoor environment is less, for that PCO doesn't show efficient performance due to high film diffusional resistance; (2) it is very difficult to increase the photocatalytic activity of reactor per unit volume since space limitation is there when doped through noble metal on $\mathrm{TiO}_{2}$. As among all the noble metal catalysts and metal oxide catalysts, Pt shows good catalytic performance over oxidation of $\mathrm{HCHO}$ at room temperature. A small addition of Pt is enough for catalytic oxidation of formaldehyde but due to some limitation of high cost which makes Pt unused for practical application. Among various catalysts, Pd shows also good catalytic activity of different support like $\mathrm{TiO}_{2}, \mathrm{Al}_{2} \mathrm{O}_{3}, \mathrm{MnO}_{2}$, $\mathrm{CeO}_{2}$, and Zeolite for the oxidation of $\mathrm{HCHO}$ and is abundantly available in nature. Negatively charged Pd supported catalysts improve the catalytic oxidation. For enhanced catalytic oxidation of $\mathrm{HCHO}$ with improved structure and chemical state, Pd species done well. With the proper support of metal oxide and with different morphology Pd catalysts can easily oxidize $\mathrm{HCHO}$ in $\mathrm{CO}_{2}$, and $\mathrm{H}_{2} \mathrm{O}$ at even room temperature. For lowering the temperature for catalytic oxidation addition of alkali plays an effective factor also. This effect is discussed in Table 2. Another noble metal, gold also does an influencing catalytic oxidation with well-defined morphology such as: three-dimensionally ordered macroporous with nanowalls.

There are some disadvantages noticed as well except the cost is poorly resistant to poisoning. Other than this, manganese oxide exhibits good catalytic properties to the different oxidation states available. Manganese and ceria oxide supports are well in oxygen storage capacity, redox properties, and thermal resistance. Different morphological changes like pyrolusite, cryptomelane, and todorokite in the case of $\mathrm{MnO}_{x}$ have a strong effect on reaction rate. The addition of noble metal over the transition metal oxide supported catalyst also improves the catalytic degradation of $\mathrm{HCHO}$ and makes the transition oxide catalysts preferable for the environmental temperature condition. The various structure has been used for enhancing the property of metal oxide such as $\mathrm{CeO}_{2}$ nanorods, graphene support $\mathrm{MnO}_{x}$, manganese dioxide nano-sheets on cellulose fibers, nano- $\mathrm{Co}_{3} \mathrm{O}_{4}, 3 \mathrm{D}-\mathrm{Co}_{3} \mathrm{O}_{4}$ and $2 \mathrm{D}-\mathrm{Co}_{3} \mathrm{O}_{4}$.

\section{Conclusion}

In this article, the most popular techniques for formaldehyde degradation i.e. photocatalytic oxidation and catalytic oxidation have been discussed. In spite of availability of efficient catalysts, the challenging work concern over higher efficiency, optimum design, and low cost availability. Moreover, the catalytic degradation of HCHO through the catalytic oxidation with noble metal and transitional metals supported metal oxide is emphasized in this review paper. To do this catalytic oxidation process subdivided into two main section; noble metal and metal oxide catalysts which give further insights the dependency of relative humidity, calcination temperature, preparation method, feed rate, morphology, addition of metal. In recent years a lot of work has been carried out on lowering temperature of oxidation of $\mathrm{HCHO}$ to room temperature with noble metal-supported metal oxide and transitional metal oxide.

In various articles, different groups have worked on nanostructures, reduction properties, active surface area, etc. So, the recent work corresponding to the degradation of indoor HCHO has been focused on designing and finding effective support like graphene, cotton, $\mathrm{ZnO}$. Current work also just focused on varying operating parameters like preparation method, calcination temperature, the oxidation state of metals, etc. The addition of alkali, rare Earth metal to the supported catalyst is still not cleared with transition metal oxide. Other degradation processes like thermocatalytic process are also used but possess the difficulty of conversion of $\mathrm{HCHO}$ into $\mathrm{CO}_{2}$ at ambient condition. Advanced processes are using this process with modification in morphology, concentration etc. to completely degrade the $\mathrm{HCHO}$ from the indoor environment. Element like $\mathrm{MnO}_{2}$, without proper morphology and additives cannot enhance rate of degradation. The role of HCHO concentration, space velocity, and water vapor strongly affect the catalytic oxidation of HCHO. Long-time stability of catalyst and formation of the intermediate products are still a major concern for the practical application. In recent years, research work has been 
concentrated on complete catalytic oxidation of $\mathrm{HCHO}$ at ambient temperature. Some works are really appreciable in this context. But there is still a large gap of their practical uses either due to cost or intermediate product limitation. However, the development of effective low-cost catalyst formation is the biggest work that has to be done. The work on transition metal oxides like $\left(\mathrm{MnO}_{2}, \mathrm{CeO}_{2}\right)$ still needs a proper synthesis to work on room temperature of influencing the removal of formaldehyde.

Author contribution: All the authors have accepted responsibility for the entire content of this submitted manuscript and approved submission.

Research funding: None declared.

Conflict of interest statement: The authors declare no conflicts of interest regarding this article.

\section{References}

Adjimi, S., J. C. Roux, N. Sergent, F. Delpech, P. X. Thivel, and M. Pera-Titus. 2014. "Photocatalytic Oxidation of Ethanol Using Paper-Based Nano- $\mathrm{TiO}_{2}$ Immobilized on Porous Silica: A Modelling Study." Chemical Engineering Journal 251: 381-91.

Akbarzadeh, R., S. B. Umbarkar, R. S. Sonawane, S. Takle, and M. K. Dongare. 2010. "Vanadia-Titania Thin Films for Photocatalytic Degradation of Formaldehyde in Sunlight." Applied Catalysis A: General 374 (1): 103-9.

Alexeev, O. S., S. Y. Chin, M. H. Engelhard, L. Ortiz-Soto, and M. D. Amiridis. 2005. "Effects of Reduction Temperature and Metal-Support Interactions on the Catalytic Activity of $\mathrm{Pt} / \mathrm{Y}-\mathrm{Al}_{2} \mathrm{O}_{3}$ and $\mathrm{Pt} / \mathrm{TiO}_{2}$ for the Oxidation of $\mathrm{CO}$ in the Presence and Absence of $\mathrm{H}_{2}$." The Journal of Physical Chemistry B 109 (49): 23430-43.

Álvarez-Galván, M. C., B. Pawelec, V. A. De la Peña O’Shea, J. L. Fierro, and P. L. Arias. 2004. "Formaldehyde/Methanol Combustion on Alumina-Supported Manganese-Palladium Oxide Catalyst.” Applied Catalysis B: Environmental 51 (2): 83-91.

An, N., Q. Yu, G. Liu, S. Li, M. Jia, and W. Zhang. 2011. "Complete Oxidation of Formaldehyde at Ambient Temperature over Supported $\mathrm{Pt} / \mathrm{Fe}_{2} \mathrm{O}_{3}$ Catalysts Prepared by Colloid-Deposition Method." Journal of Hazardous Materials 186 (2): 1392-7.

An, N., P. Wu, S. Li, M. Jia, and W. Zhang. 2013. "Catalytic Oxidation of Formaldehyde over $\mathrm{Pt} / \mathrm{Fe}_{2} \mathrm{O}_{3}$ Catalysts Prepared by Different Method." Applied Surface Science 285: 805-9.

Anpo, M., I. Tanahashi, and Y. Kubokawa. 1980. "Photoluminescence and Photoreduction of Vanadium Pentoxide Supported on Porous Vycor Glass." The Journal of Physical Chemistry 84 (25): 3440-3.

Anpo, M., N. Aikawa, Y. Kubokawa, M. Che, C. Louis, and E. Giamello. 1985. "Photoluminescence and Photocatalytic Activity of Highly Dispersed Titanium Oxide Anchored onto Porous Vycor Glass.” The Journal of Physical Chemistry 89 (23): 5017-21.

Anpo, M., H. Yamashita, S. Kanai, K. Sato, T. Fujimoto, inventors, and Petroleum Energy Center, assignee 2000. "Photocatalyst, process for producing the photocatalyst, and photocatalytic reaction method." United States patent US 6,077,492. 2000.
Arzamendi, G., V. A. de la Peña O’Shea, M. C. Álvarez-Galván, J. L. Fierro, P. L. Arias, and L. M. Gandía. 2009. "Kinetics and Selectivity of Methyl-Ethyl-Ketone Combustion in Air over Alumina-Supported $\mathrm{PdO}_{X}-\mathrm{MnO}_{X}$ Catalysts." Journal of Catalysis 261 (1): 50-9.

Asahi, R. Y., T. A. Morikawa, T. Ohwaki, K. Aoki, and Y. Taga. 2001. "Visible-Light Photocatalysis in Nitrogen-Doped Titanium Oxides." Science 293 (5528): 269-71.

Bai, B., and J. Li. 2014. "Positive Effects of $\mathrm{K}^{+}$Ions on ThreeDimensional Mesoporous $\mathrm{Ag} / \mathrm{CO}_{3} \mathrm{O}_{4}$ Catalyst for $\mathrm{HCHO}$ Oxidation." ACS Catalysis 4 (8): 2753-62.

Bai, B., H. Arandiyan, and J. Li. 2013. "Comparison of the Performance for Oxidation of Formaldehyde on Nano- $\mathrm{CO}_{3} \mathrm{O}_{4}, 2 \mathrm{D}-\mathrm{CO}_{3} \mathrm{O}_{4}$, and 3D- $\mathrm{CO}_{3} \mathrm{O}_{4}$ Catalysts." Applied Catalysis B: Environmental 142: 677-83.

Benz, L., J. Haubrich, R. G. Quiller, S. C. Jensen, and C. M. Friend. 2009. "McMurry Chemistry on $\mathrm{TiO}_{2}$ (110): Reductive $\mathrm{C}=\mathrm{C}$ Coupling of Benzaldehyde Driven by Titanium Interstitials." Journal of the American Chemical Society 131 (41): 15026-31.

Bollinger, M. A., and M. A. Vannice. 1996. "A Kinetic and DRIFTS Study of Low-Temperature Carbon Monoxide Oxidation Over $\mathrm{Au}-\mathrm{TiO}_{2}$ Catalysts." Applied Catalysis B: Environmental 8 (4): 417-43.

Bowker, M., and R. A. Bennett. 2009. "The Role of $\mathrm{Ti}^{3+}$ Interstitials in $\mathrm{TiO}_{2}$ (110) Reduction and Oxidation." Journal of Physics: Condensed Matter 21 (47): 474224.

Boyjoo, Y., H. Sun, J. Liu, V. K. Pareek, and S. Wang. 2017. "A Review on Photocatalysis for Air Treatment: from Catalyst Development to Reactor Design." Chemical Engineering Journal 310: 537-59.

Chen, H., J. He, C. Zhang, and H. He. 2007. "Self-Assembly of Novel Mesoporous Manganese Oxide Nanostructures and their Application in Oxidative Decomposition of Formaldehyde." The Journal of Physical Chemistry C 111 (49): 18033-8.

Chen, T., H. Dou, X. Li, X. Tang, J. Li, and J. Hao. 2009. “Tunnel Structure Effect of Manganese Oxides in Complete Oxidation of Formaldehyde." Microporous and Mesoporous Materials 122 (1): 270-4.

Chen, B. B., C. Shi, M. Crocker, Y. Wang, and A. M. Zhu. 2013. "Catalytic Removal of Formaldehyde at Room Temperature over Supported Gold Catalysts." Applied Catalysis B: Environmental 132: 245-55.

Chen, Y., J. He, H. Tian, D. Wang, and Q. Yang. 2014. "Enhanced Formaldehyde Oxidation on $\mathrm{Pt} / \mathrm{MnO}_{2}$ Catalysts Modified with Alkali Metal Salts." Journal of Colloid and Interface Science 428: 1-7.

Cordi, E. M., and J. L. Falconer. 1996. "Oxidation of Volatile Organic Compounds on $\mathrm{Al}_{2} \mathrm{O}_{3}, \mathrm{Pd} / \mathrm{Al}_{2} \mathrm{O}_{3}$, and $\mathrm{PdO} / \mathrm{Al}_{2} \mathrm{O}_{3}$ Catalysts." Journal of Catalysis 162 (1): 104-17.

de la Peña O’Shea, V. A., M. C. Alvarez-Galvan, J. L. Fierro, and P. L. Arias. 2005. "Influence of Feed Composition on the Activity of $\mathrm{Mn}$ and $\mathrm{PdMn} / \mathrm{Al}_{2} \mathrm{O}_{3}$ Catalysts for Combustion of Formaldehyde/Methanol." Applied Catalysis B: Environmental 57 (3): 191-9.

Delannoy, L., K. Fajerwerg, P. Lakshmanan, C. Potvin, C. Méthivier, and C. Louis. 2010. "Supported Gold Catalysts for the Decomposition of VOC: Total Oxidation of Propene in Low Concentration as Model Reaction." Applied Catalysis B: Environmental 94 (1): 117-24.

Deng, X. Q., J. L. Liu, X. S. Li, B. Zhu, X. Zhu, and A. M. Zhu. 2017. "Kinetic Study on Visible-Light Photocatalytic Removal of 
Formaldehyde from Air over Plasmonic $\mathrm{Au} / \mathrm{TiO}_{2}$." Catalysis Today 281: 630-5.

Ding, H. X., A. M. Zhu, F. G. Lu, Y. Xu, J. Zhang, and X. F. Yang. 2006. "Low-temperature Plasma-Catalytic Oxidation of Formaldehyde in Atmospheric Pressure Gas Streams." Journal of Physics D: Applied Physics 39 (16): 3603.

Dobrosz-Gómez, I., I. Kocemba, and J. M. Rynkowski. 2008. “Au/ $\mathrm{Ce}_{1-x} \mathrm{Zr}_{x} \mathrm{O}_{2}$ as Effective Catalysts for Low-Temperature $\mathrm{CO}$ Oxidation." Applied Catalysis B: Environmental 83 (3): 240-55.

Domingo-Garcia, M., I. Fernández-Morales, F. J. Lopez-Garzon, C. Moreno-Castilla, and M. Perez-Mendoza. 1999. "On the Adsorption of Formaldehyde at High Temperatures and Zero Surface Coverage." Langmuir 15 (9): 3226-31.

Feng, Y., I. S. Cho, L. Cai, P. M. Rao, and X. Zheng. 2013. "Sol-Flame Synthesis of Hybrid Metal Oxide Nanowires." Proceedings of the Combustion Institute 34 (2): 2179-86.

Fu, P., P. Zhang, and J. Li. 2011. "Photocatalytic Degradation of Low Concentration Formaldehyde and Simultaneous Elimination of Ozone By-product using Palladium Modified TiO2 Films Under UV254+185nm irradiation." Applied Catalysis B: Environmental 105: 220.

Gluhoi, A. C., N. Bogdanchikova, and B. E. Nieuwenhuys. 2005. "The Effect of Different Types of Additives on the Catalytic Activity of $\mathrm{Au} / \mathrm{Al}_{2} \mathrm{O}_{3}$ in Propene Total Oxidation: Transition Metal Oxides and Ceria." Journal of Catalysis 229 (1): 154-62.

Goode, J. W. 1985. "Toxicology of Formaldehyde." Advances in Chemistry 210: 217-27.

Goswami, D. Y. 1998. "Photocatalytic System for Indoor Air Quality," US Patent Serial No. 5,835,840, November 10, 1998.

Goswami, D. Y. 1999a. “Photocatalytic Air Disinfection.” U.S. Patent Serial No. 5,933,702 August 3, 1999.

Goswami, D. Y. 1999b. "Electrostatic Photocatalytic Air Disinfection," U.S. Patent Serial No. 5,993,738, November 30, 1999.

Goswami, D. Y. 2003. "Decontamination of Ventilation Systems Using Photocatalytic Air Cleaning Technology." Journal of Solar Energy Engineering 125 (3): 359-65.

Goswami, D. Y. 2008. "Enhanced Photocatalytic Air Detoxification and Disinfection by Active Electron Transfer.” US Patent No 7,371,351, May 13, 2008.

Goswami, D. Y., D. M. Trivedi, and S. S. Block. 1997. "Photocatalytic Disinfection of Indoor Air." Journal of Solar Energy Engineering 119 (1): 92-6.

Groppi, G., and E. Tronconi. 2005. "Honeycomb Supports with High Thermal Conductivity for Gas/solid Chemical Processes." Catalysis Today 105 (3): 297-304.

Gupta, J., K. C. Barick, and D. Bahadur. 2011. “Defect Mediated Photocatalytic Activity in Shape-Controlled ZnO Nanostructures." Journal of Alloys and Compounds 509 (23): 6725-30

Haruta, M., N. Yamada, T. Kobayashi, and S. lijima. 1989. "Gold Catalysts Prepared by Coprecipitation for Low-Temperature Oxidation of Hydrogen and of Carbon Monoxide." Journal of Catalysis 115 (2): 301-9.

Hashimoto, K., H. Irie, and A. Fujishima. 2005. " $\mathrm{TiO}_{2}$ Photocatalysis Historical Overview and Future Prospect." Japanese Journal of Applied Physics. Part 144 (12): 8269-85.

Hoffmann, M. R., S. T. Martin, W. Choi, and D. W. Bahnemann. 1995. "Environmental Applications of Semiconductor Photocatalysis." Chemical Reviews 95 (1): 69-96.
Hong, Y. C., K. Q. Sun, K. H. Han, G. Liu, and B. Q. Xu. 2010. "Comparison of Catalytic Combustion of Carbon Monoxide and Formaldehyde over $\mathrm{Au} / \mathrm{ZrO}_{2}$ Catalysts." Catalysis Today 158 (3): 415-22.

Hosseini, M., T. Barakat, R. Cousin, A. Aboukaïs, B. L. Su, G. De Weireld, and S. Siffert. 2012. "Catalytic Performance of Core-Shell and Alloy Pd-Au Nanoparticles for Total Oxidation of VOC: The Effect of Metal Deposition." Applied Catalysis B: Environmental 111: 218-24.

Hu, P., Z. Amghouz, Z. Huang, F. Xu, Y. Chen, and X. Tang. 2015. "Surface-confined Atomic Silver Centers Catalyzing Formaldehyde Oxidation." Environmental Science \& Technology 49 (4): 2384-90.

Huang, H., and D. Y. Leung. 2011a. “Complete Oxidation of Formaldehyde at Room Temperature Using $\mathrm{TiO}_{2}$ Supported Metallic Pd Nanoparticles." ACS Catalysis 1 (4): 348-54.

Huang, H., and D. Y. Leung. 2011b. "Complete Elimination of Indoor Formaldehyde Over Supported Pt Catalysts with Extremely Low Pt Content at Ambient Temperature." Journal of Catalysis 280 (1): 60-7.

Huang, H., X. Ye, H. Huang, L. Zhang, and D. Y. Leung. 2013a. "Mechanistic Study on Formaldehyde Removal over Pd/TiO Catalysts: Oxygen Transfer and Role of Water Vapor." Chemical Engineering Journal 230: 73-9.

Huang, Q., W. Ma, X. Yan, Y. Chen, S. Zhu, and S. Shen. 2013b. "Photocatalytic Decomposition of Gaseous $\mathrm{HCHO}$ by $\mathrm{Zr}_{x} \mathrm{Ti}_{1-x} \mathrm{O}_{2}$ Catalysts under UV-Vis Light Irradiation with an EnergySaving Lamp." Journal of Molecular Catalysis A: Chemical 366: 261-5.

Ibhadon, A. O., I. M. Arabatzis, P. Falaras, and D. Tsoukleris. 2007. "The Design and Photoreaction Kinetic Modeling of a Gas-Phase Titania Foam Packed Bed Reactor." Chemical Engineering Journal 133 (1-3): 317-23.

Imamura, S., Y. Uematsu, K. Utani, and T. Ito. 1991. "Combustion of Formaldehyde on Ruthenium/cerium (IV) Oxide Catalyst." Industrial \& Engineering Chemistry Research 30 (1): 18-21.

Imamura, S., D. Uchihori, K. Utani, and T. Ito. 1994. "Oxidative Decomposition of Formaldehyde on Silver-Cerium Composite Oxide Catalyst." Catalysis Letters 24 (3): 377-84.

Jin, M., X. Zhang, S. Nishimoto, Z. Liu, D. A. Tryk, A. V. Emeline, T. Murakami, and A. Fujishima. 2007. "Light-stimulated Composition Conversion in $\mathrm{TiO}_{2}$-Based Nanofibers." The Journal of Physical Chemistry C 111 (2): 658-65.

Kecskés, T., J. Raskó, and J. Kiss. 2004. "FTIR and Mass Spectrometric Studies on the Interaction of Formaldehyde with $\mathrm{TiO}_{2}$ Supported Pt and Au Catalysts." Applied Catalysis A: General 273 (1): 55-62.

Khan, S. U., M. Al-Shahry, and W. B. Ingler. 2002. "Efficient photochemical water splitting by a chemically modified $n$ - $\mathrm{TiO}_{2}$." Science 297 (5590): 2243-5.

Kim, S. S., K. H. Park, and S. C. Hong. 2011. "A Study on HCHO Oxidation Characteristics at Room Temperature Using a Pt/TiO Catalyst.” Applied Catalysis A: General 398 (1): 96-103.

Kocareva, T., I. Grozdanov, and B. Pejova. 2001. "Ag and AgO Thin Film Formation in $\mathrm{Ag}^{+}$-Triethanolamine Solutions." Materials Letters 47 (6): 319-23.

Kołodziej, A., and J. Łojewska. 2005. "Optimization of Structured Catalyst Carriers for VOC Combustion.” Catalysis Today 105 (3): 378-84.

Kwon, D. W., P. W. Seo, G. J. Kim, and S. C. Hong. 2015. "Characteristics of the $\mathrm{HCHO}$ Oxidation Reaction over $\mathrm{Pt} / \mathrm{TiO}_{2}$ 
Catalysts at Room Temperature: The Effect of Relative Humidity on Catalytic Activity." Applied Catalysis B: Environmental 163: 436-43.

Lam, R. C., M. K. Leung, D. Y. Leung, L. L. Vrijmoed, W. C. Yam, and S. P. Ng. 2007. "Visible-Light-Assisted Photocatalytic Degradation of Gaseous Formaldehyde by Parallel-Plate Reactor Coated with $\mathrm{Cr}$ lon-Implanted $\mathrm{TiO}_{2}$ Thin Film." Solar Energy Materials and Solar Cells 91 (1): 54-61.

Landis, E. C., S. C. Jensen, K. R. Phillips, and C. M. Friend. 2012. "Photostability and Thermal Decomposition of Benzoic Acid on $\mathrm{TiO}_{2}$." The Journal of Physical Chemistry C 116 (40): 21508-13.

Li, S. C., and U. Diebold. 2009. "Reactivity of $\mathrm{TiO}_{2}$ Rutile and Anatase Surfaces toward Nitroaromatics." Journal of the American Chemical Society 132 (1): 64-6.

Li, C. Y., Y. N. Shen, R. S. Hu, P. P. Li, and J. Zhang. 2007. "Catalytic Activity of Au/Fe-PILC and Au/Fe-Oxide Catalysts for Catalytic Combustion of Formaldehyde." Transactions of Nonferrous Metals Society of China 17 (s1B): s1107-11.

Li, C., Y. Shen, M. Jia, S. Sheng, M. O. Adebajo, and H. Zhu. 2008. "Catalytic Combustion of Formaldehyde on Gold/Iron-Oxide Catalysts." Catalysis Communications 9 (3): 355-61.

Li, Y., Y. Jiang, S. Peng, and F. Jiang. 2010. "Nitrogen-doped $\mathrm{TiO}_{2}$ Modified with $\mathrm{NH}_{4} \mathrm{~F}$ for Efficient Photocatalytic Degradation of Formaldehyde under Blue Light-Emitting Diodes." Journal of Hazardous Materials 182 (1): 90-6.

Li, H. F., N. Zhang, P. Chen, M. F. Luo, and J. Q. Lu. 2011. “High Surface Area $\mathrm{Au} / \mathrm{CeO}_{2}$ Catalysts for Low Temperature Formaldehyde Oxidation." Applied Catalysis B: Environmental 110: 279-85.

Li, J. W., K. L. Pan, S. J. Yu, S. Y. Yan, and M. B. Chang. 2014. "Removal of Formaldehyde over $\mathrm{Mn}_{x} \mathrm{Ce}_{1-x} \mathrm{O}_{2}$ Catalysts: Thermal Catalytic Oxidation Versus Ozone Catalytic Oxidation." Journal of Environmental Sciences 26 (12): 2546-53.

Li, D., G. Yang, P. Li, J. Wang, and P. Zhang. 2016a. "Promotion of Formaldehyde Oxidation over $\mathrm{Ag}$ Catalyst by Fe Doped $\mathrm{MnO}_{x}$ Support at Room Temperature." Catalysis Today 277: 257-65.

Li, Y., C. Zhang, H. He, J. Zhang, and M. Chen. 2016b. "Influence of Alkali Metals on $\mathrm{Pd} / \mathrm{TiO}_{2}$ Catalysts for Catalytic Oxidation of Formaldehyde at Room Temperature." Catalysis Science \& Technology 6 (7): 2289-95.

Li, Y., C. Zhang, and H. He. 2017. "Significant Enhancement in Activity of $\mathrm{Pd} / \mathrm{TiO}_{2}$ Catalyst for Formaldehyde Oxidation by $\mathrm{Na}$ Addition." Catalysis Today 281: 412-7.

Liang, W. J., J. Li, J. X. Li, T. Zhu, and Y. Q. Jin. 2010. “Formaldehyde Removal from Gas Streams by Means of $\mathrm{NaNO}_{2}$ Dielectric Barrier Discharge Plasma." Journal of Hazardous Materials 175 (1): 1090-5.

Liang, W., J. Li, and Y. Jin. 2012. "Photo-catalytic Degradation of Gaseous Formaldehyde by $\mathrm{TiO}_{2} / \mathrm{UV}, \mathrm{Ag} / \mathrm{TiO}_{2} / \mathrm{UV}$ and $\mathrm{Ce} / \mathrm{TiO}_{2} /$ UV." Building and Environment 51: 345-50.

Liao, Y., C. Xie, Y. Liu, and Q. Huang. 2013. "Enhancement of Photocatalytic Property of $\mathrm{ZnO}$ for Gaseous Formaldehyde Degradation by Modifying Morphology and Crystal Defect." Journal of Alloys and Compounds 550: 190-7.

Lin, L., W. Lin, J. L. Xie, Y. X. Zhu, B. Y. Zhao, and Y. C. Xie. 2007. "Photocatalytic Properties of Phosphor-Doped Titania Nanoparticles." Applied Catalysis B: Environmental 75 (1): 52-8.

Liotta, L. F. 2010. "Catalytic Oxidation of Volatile Organic Compounds on Supported Noble Metals." Applied Catalysis B: Environmental 100 (3): 403-12.

Liu, S. H., and W. X. Lin. 2019. "A Simple Method to Prepare G- $\mathrm{C}_{3} \mathrm{~N}_{4}$ $\mathrm{TiO}_{2} /$ Waste Zeolites as Visible-Light-Responsive Photocatalytic
Coatings for Degradation of Indoor Formaldehyde." Journal of Hazardous Materials 15 (368): 468-76.

Liu, Y., C. Y. Liu, Q. H. Rong, and Z. Zhang. 2003. "Characteristics of the Silver-Doped $\mathrm{TiO}_{2}$ Nanoparticles.” Applied Surface Science 220 (1): 7-11.

Liu, H. Y., X. J. Wang, L. P. Wang, F. Y. Lei, X. F. Wang, and H. J. Ai. 2008. "Effect of Fluoride-Ion Implantation on the Biocompatibility of Titanium for Dental Applications." Applied Surface Science 254 (20): 6305-12.

Liu, L., H. Tian, J. He, D. Wang, and Q. Yang. 2012a. "Preparation of Birnessite-Supported Pt Nanoparticles and their Application in Catalytic Oxidation of Formaldehyde." Journal of Environmental Sciences 24 (6): 1117-24.

Liu, B., C. Li, Y. Zhang, Y. Liu, W. Hu, Q. Wang, L. Han, and J. Zhang. 2012b. "Investigation of Catalytic Mechanism of Formaldehyde Oxidation over Three-Dimensionally Ordered Macroporous Au/ $\mathrm{CeO}_{2}$ Catalyst." Applied Catalysis B: Environmental 111: 467-75.

Liu, B., Y. Liu, C. Li, W. Hu, P. Jing, Q. Wang, and J. Zhang. 2012c. "Three-dimensionally Ordered Macroporous $\mathrm{Au} / \mathrm{CeO}_{2}-\mathrm{CO}_{3} \mathrm{O}_{4}$ Catalysts with Nanoporous Walls for Enhanced Catalytic Oxidation of Formaldehyde." Applied Catalysis B: Environmental 127: 47-58.

Lu, G., A. Linsebigler, and J. T. Yates Jr. 1994. " $\mathrm{Ti}^{3+}$ Defect Sites on $\mathrm{TiO}_{2}$ (110): Production and Chemical Detection of Active Sites." The Journal of Physical Chemistry 98 (45): 11733-8.

Lu, L., H. Tian, J. He, and Q. Yang. 2016. "Graphene- $\mathrm{MnO}_{2}$ Hybrid Nanostructure as a New Catalyst for Formaldehyde Oxidation." The Journal of Physical Chemistry C 120 (41): 23660-8.

Ma, C., D. Wang, W. Xue, B. Dou, H. Wang, and Z. Hao. 2011. "Investigation of Formaldehyde Oxidation over $\mathrm{CO}_{3} \mathrm{O}_{4}-\mathrm{CeO}_{2}$ and $\mathrm{Au} / \mathrm{CO}_{3} \mathrm{O}_{4}-\mathrm{CeO}_{2}$ Catalysts at Room Temperature: Effective Removal and Determination of Reaction Mechanism." Environmental Science \& Technology 45 (8): 3628-34.

$\mathrm{Ma}$, L., D. Wang, J. Li, B. Bai, L. Fu, and Y. Li. 2014. “Ag/ $\mathrm{CeO}_{2}$ Nanospheres: Efficient Catalysts for Formaldehyde Oxidation." Applied Catalysis B: Environmental 148: 36-43.

Matsuo, Y., Y. Nishino, T. Fukutsuka, and Y. Sugie. 2008. "Removal of Formaldehyde from Gas Phase by Silylated Graphite Oxide Containing Amino Groups.” Carbon 46 (8): 1162-3.

Mirkelamoglu, B., and G. Karakas. 2006. "The Role of Alkali-Metal Promotion on $\mathrm{CO}$ Oxidation over $\mathrm{PdO} / \mathrm{SnO}_{2}$ Catalysts." Applied Catalysis A: General 299: 84-94.

Nie, L., J. Yu, X. Li, B. Cheng, G. Liu, and M. Jaroniec. 2013. "Enhanced Performance of $\mathrm{NaOH}-$ Modified $\mathrm{Pt} / \mathrm{TiO}_{2}$ toward Room Temperature Selective Oxidation of Formaldehyde." Environmental Science \& Technology 47 (6): 2777-83.

Noguchi, T., A. Fujishima, P. Sawunyama, and K. Hashimoto. 1998. "Photocatalytic Degradation of Gaseous Formaldehyde Using $\mathrm{TiO}_{2}$ Film.” Environmental Science \& Technology 32 (23): 3831-3.

Norbäck, D., C. Edling, and G. Wieslander. 1994. "Asthma Symptoms and the Sick Building Syndrome (SBS)-The Significance of Microorganisms in the Indoor Environment. Health Implications of Fungi in Indoor Environments." Air Quality Monographs 2: 229-39.

Ohno, T., M. Akiyoshi, T. Umebayashi, K. Asai, T. Mitsui, and M. Matsumura. 2004. "Preparation of S-doped $\mathrm{TiO}_{2}$ photocatalysts and their photocatalytic activities under visible light." Applied Catalysis A: General 265 (1): 115-21.

Ohtani, B. 2008. "Preparing Articles on Photocatalysis-Beyond the Illusions, Misconceptions, and Speculation.” Chemistry Letters 37 (3): 216-29. 
Ollis, D. F. 2000. "Photocatalytic purification and remediation of contaminated air and water." Comptes Rendus de l'Académie des Sciences-Series IIC-Chemistry 3 (6): 405-11.

Ordóñez, S., L. Bello, H. Sastre, R. Rosal, and F. V. Díez. 2002. "Kinetics of the Deep Oxidation of Benzene, Toluene, N-Hexane and their Binary Mixtures over a Platinum on $\mathrm{y}$-Alumina Catalyst." Applied Catalysis B: Environmental 38 (2): 139-49.

Park, S. J., I. Bae, I. S. Nam, B. K. Cho, S. M. Jung, and J. H. Lee. 2012. "Oxidation of Formaldehyde over Pd/Beta Catalyst." Chemical Engineering Journal 195: 392-402.

Passalía, C., O. M. Alfano, and R. J. Brandi. 2012. "A Methodology for Modeling Photocatalytic Reactors for Indoor Pollution Control Using Previously Estimated Kinetic Parameters." Journal of Hazardous Materials 211: 357-65.

Pei, J., and J. S. Zhang. 2011. "Critical Review of Catalytic Oxidization and Chemisorption Methods for Indoor Formaldehyde Removal." HVAC \& R Research 17 (4): 476-503.

Pei, J., X. Han, and Y. Lu. 2015. "Performance and Kinetics of Catalytic Oxidation of Formaldehyde over Copper Manganese Oxide Catalyst." Building and Environment 84: 134-41.

Peng, J., and S. Wang. 2007. "Performance and Characterization of Supported Metal Catalysts for Complete Oxidation of Formaldehyde at Low Temperatures." Applied Catalysis B: Environmental 73 (3-4): 282-91.

Photong, S., and V. Boonamnuayvitaya. 2009. "Preparation and Characterization of Amine-Functionalized $\mathrm{SiO}_{2} / \mathrm{TiO}_{2}$ Films for Formaldehyde Degradation." Applied Surface Science 255 (23): 9311-5.

Popova, M., Á. Szegedi, Z. Cherkezova-Zheleva, A. Dimitrova, and I. Mitov. 2010. "Toluene Oxidation on Chromium- and CopperModified $\mathrm{SiO}_{2}$ and SBA-15." Applied Catalysis A: General 381 (1): 26-35.

Qin, Y., Z. Wang, J. Jiang, L. Xing, and K. Wu. 2020. “One-step Fabrication of $\mathrm{TiO}_{2} / \mathrm{Ti}$ Foil Annular Photoreactor for Photocatalytic Degradation of Formaldehyde." Chemical Engineering Journal: 124917. https://doi.org/10.1016/j.cej. 2020.124917.

Reed, J., and G. Ceder. 2004. "Role of Electronic Structure in the Susceptibility of Metastable Transition-Metal Oxide Structures to Transformation." Chemical Reviews 104 (10): 4513-34.

Scire, S., S. Minico, C. Crisafulli, C. Satriano, and A. Pistone. 2003. "Catalytic Combustion of Volatile Organic Compounds on Gold/ cerium Oxide Catalysts." Applied Catalysis B: Environmental 40 (1): 43-9.

Sekine, Y. 2002. “Oxidative Decomposition of Formaldehyde by Metal Oxides at Room Temperature." Atmospheric Environment 36 (35): 5543-7.

Serre, C., F. Garin, G. Belot, and G. Maire. 1993. "Reactivity of $\mathrm{Pt} / \mathrm{Al}_{2} \mathrm{O}_{3}$ and $\mathrm{Pt}-\mathrm{CeO}_{2} \mathrm{Al}_{2} \mathrm{O}_{3}$ Catalysts for the Oxidation of Carbon Monoxide by Oxygen: II. Influence of the Pretreatment Step on the Oxidation Mechanism." Journal of Catalysis 141 (1): 9-20.

Shi, J., H. N. Cui, Z. Liang, X. Lu, Y. Tong, C. Su, and H. Liu. 2011. "The Roles of Defect States in Photoelectric and Photocatalytic Processes for $\mathrm{Zn}_{x} \mathrm{Cd}_{1-x} \mathrm{~S}$." Energy \& Environmental Science 4 (2): 466-70.

Shi, C., Y. Wang, A. Zhu, B. Chen, and C. Au. 2012a. " $\mathrm{Mn}_{x} \mathrm{CO}_{3-} \mathrm{O}_{4}$ Solid Solution as High-Efficient Catalysts for Low-Temperature Oxidation of Formaldehyde." Catalysis Communications 28: 18-22.

Shi, C., B. B. Chen, X. S. Li, M. Crocker, Y. Wang, and A. M. Zhu. 2012b. "Catalytic Formaldehyde Removal by "Storage-oxidation"
Cycling Process over Supported Silver Catalysts." Chemical Engineering Journal 200: 729-37.

Singh, P., and S. R. Chauhan. 2016. "Carbonyl and Aromatic Hydrocarbon Emissions from Diesel Engine Exhaust Using Different Feedstock: A Review." Renewable and Sustainable Energy Reviews 63: 269-91.

Sinha, A. K., K. Suzuki, M. Takahara, H. Azuma, T. Nonaka, N. Suzuki, and N. Takahashi. 2008. "Preparation and Characterization of Mesostructured $\gamma$-manganese Oxide and its Application to VOCs Elimination." The Journal of Physical Chemistry C 112 (41): 16028-35.

Skrobot, F. C., A. A. Valente, G. Neves, I. Rosa, J. Rocha, and J. A. S. Cavaleiro. 2003. "Monoterpenes Oxidation in the Presence of Y Zeolite-Entrapped Manganese (III) Tetra (4-Nbenzylpyridyl) Porphyrin." Journal of Molecular Catalysis A: Chemical 201: 211.

Su, J., C. Cheng, Y. Guo, H. Xu, and Q. Ke. 2019. "OMS-2-Based Catalysts with Controllable Hierarchical Morphologies for Highly Efficient Catalytic Oxidation of Formaldehyde." Journal of Hazardous Materials 15 (380): 120890.

Tan, H., J. Wang, S. Yu, and K. Zhou. 2015. "Support MorphologyDependent Catalytic Activity of $\mathrm{Pd} / \mathrm{CeO}_{2}$ for Formaldehyde Oxidation." Environmental Science \& Technology 49 (14): 8675-82.

Tang, X., J. Chen, Y. Li, Y. Li, Y. Xu, and W. Shen. 2006a. "Complete Oxidation of Formaldehyde over $\mathrm{Ag} / \mathrm{MnO}_{x}-\mathrm{CeO}_{2}$ Catalysts." Chemical Engineering Journal 118 (1-2): 119-25.

Tang, X., Y. Li, X. Huang, Y. Xu, H. Zhu, J. Wang, and W. Shen. 2006b. " $\mathrm{MnO}_{X}-\mathrm{CeO}_{2}$ Mixed Oxide Catalysts for Complete Oxidation of Formaldehyde: Effect of Preparation Method and Calcination Temperature.” Applied Catalysis B: Environmental 62 (3): 265-73.

Tang, X., J. Chen, X. Huang, Y. Xu, and W. Shen. 2008. " $\mathrm{Pt} / \mathrm{MnO}_{X}-\mathrm{CeO}_{2}$ Catalysts for the Complete Oxidation of Formaldehyde at Ambient Temperature." Applied Catalysis B: Environmental 81 (1): $115-21$.

Terelak, K., S. Trybula, M. Majchrzak, M. Ott, and H. Hasse. 2005. "Pilot Plant Formaldehyde Distillation: Experiments and Modelling." Chemical Engineering and Processing: Process Intensification 44 (6): 671-6.

Tian, H., J. He, L. Liu, D. Wang, Z. Hao, and C. Ma. 2012. “Highly Active Manganese Oxide Catalysts for Low-Temperature Oxidation of Formaldehyde." Microporous and Mesoporous Materials 151: 397-402.

Tompkins D. T. 2001. "Evaluation of Photocatalytic Air Cleaning Capability: a Literature Review and Engineering Analysis." ASHARE Research Project RP-1134.

Tsukamoto, D., Y. Shiraishi, Y. Sugano, S. Ichikawa, S. Tanaka, and T. Hirai. 2012. "Gold Nanoparticles Located at the Interface of Anatase/Rutile $\mathrm{TiO}_{2}$ Particles as Active Plasmonic Photocatalysts for Aerobic Oxidation." Journal of the American Chemical Society 134 (14): 6309-15.

Ubolchonlakate, K., L. Sikong, and T. Tontai. 2010. "Formaldehyde Degradation by Photocatalytic Ag-Doped $\mathrm{TiO}_{2}$ Film of Glass Fiber Roving." Journal of Nanoscience and Nanotechnology 10 (11): 7522-5.

Venkataraj, S., O. Kappertz, R. Drese, C. Liesch, R. Jayavel, and M. Wuttig. 2002. "Thermal Stability of Lead Oxide Films Prepared by Reactive DC Magnetron Sputtering." Physica Status Solidi (a) 194 (1): 192-205. 
Veser, G., M. Ziauddin, and L. D. Schmidt. 1999. "Ignition in Alkane Oxidation on Noble-Metal Catalysts." Catalysis Today 47 (1): 219-28.

Vijayakrishnan, V., A. Chainani, D. D. Sarma, and C. N. Rao. 1992. "Metal-insulator Transitions in Metal Clusters: A High-Energy Spectroscopy Study of Palladium and Silver Clusters." The Journal of Physical Chemistry 96 (22): 8679-82.

Villegas, J. C., L. J. Garces, S. Gomez, J. P. Durand, and S. L. Suib. 2005. "Particle Size Control of Cryptomelanenanomaterials by Use of $\mathrm{H}_{2} \mathrm{O}_{2}$ in Acidic Conditions." Chemistry of Materials 17 (7): 1910-8.

Vohra, A., D. Y. Goswami, D. A. Deshpande, and S. S. Block. 2005. "Enhanced Photocatalytic Inactivation of Bacterial Spores on Surfaces in Air." Journal of Industrial Microbiology and Biotechnology 32 (8): 364.

Vohra, A., D. Y. Goswami, D. A. Deshpande, and S. S. Block. 2006. "Enhanced Photocatalytic Disinfection of Indoor Air." Applied Catalysis B: Environmental 64 (1-2): 57-65.

Wang, C., and D. Astruc. 2014. "Nano Gold Plasmonic Photocatalysis for Organic Synthesis and Clean Energy Conversion." Chemical Society Reviews 43 (20): 7188-216.

Wang, R., and J. Li. 2009. "OMS-2 Catalysts for Formaldehyde Oxidation: Effects of Ce and Pt on Structure and Performance of the Catalysts." Catalysis Letters 131 (3-4): 500-5.

Wang, R., and J. Li. 2010. "Effects of Precursor and Sulfation on OMS-2 Catalyst for Oxidation of Ethanol and Acetaldehyde at Low Temperatures." Environmental Science \& Technology 44 (11): 4282-7.

Wang, Q., J. Biener, X. C. Guo, E. Farfan-Arribas, and R. J. Madix. 2003. "Reactivity of Stoichiometric and Defective $\mathrm{TiO}_{2}$ (110) Surfaces toward DCOOD Decomposition." The Journal of Physical Chemistry B 107 (42): 11709-20.

Wang, X., J. C. Yu, Y. Chen, L. Wu, and X. Fu. 2006. " $\mathrm{ZrO}_{2}$-Modified MesoporousNanocrystalline $\mathrm{TiO}_{2-x} \mathrm{~N}_{x}$ as Efficient Visible Light Photocatalysts." Environmental Science \& Technology 40 (7): 2369-74.

Wang, S., H. M. Ang, and M. O. Tade. 2007. "Volatile Organic Compounds in Indoor Environment and Photocatalytic Oxidation: State of the Art." Environment International 33 (5): 694-705.

Wang, M. M., L. He, Y. M. Liu, Y. Cao, H. Y. He, and K. N. Fan. 2011. “Gold Supported on Mesostructured Ceria as an Efficient Catalyst for the Chemoselective Hydrogenation of Carbonyl Compounds in Neat Water." Green Chemistry 13 (3): 602-7.

Wang, B., X. Wu, R. Ran, Z. Si, and D. Weng. 2012. "Participation of Sulfates in Propane Oxidation on $\mathrm{Pt} / \mathrm{SO}_{4}{ }^{2-} / \mathrm{CeO}^{2-} \mathrm{ZrO}_{2}$ Catalyst." Journal of Molecular Catalysis A: Chemical 361: 98-103.

Wen, Y., X. Tang, J. Li, J. Hao, L. Wei, and X. Tang. 2009. “Impact of Synthesis Method on Catalytic Performance of $\mathrm{MnO}_{x}-\mathrm{SnO}_{2}$ for Controlling Formaldehyde Emission." Catalysis Communications 10 (8): 1157-60.

Wu, P. C., Y. Y. Li, C. C. Lee, C. M. Chiang, and H. J. Su. 2003. "Risk Assessment of Formaldehyde in Typical Office Buildings in Taiwan." Indoor Air 13 (4): 359-63.

Xingfu, T., X. Huang, S. Jianjun, L. I. Junlong, L. I. Yonggang, X. U. Yide, and S. H. Wenjie. 2006. "Synthesis and Catalytic Performance of Manganese Oxide Octahedral Molecular Sieve Nanorods for Formaldehyde Oxidation at Low Temperature." Chinese Journal of Catalysis 27 (2): 97-9.

Xu, Y., and M. A. Schoonen. 2000. "The Absolute Energy Positions of Conduction and Valence Bands of Selected Semiconducting Minerals." American Mineralogist 85 (3-4): 543-56.
Xu, Z., N. Qin, J. Wang, and H. Tong. 2010. "Formaldehyde Biofiltration as Affected by Spider Plant.” Bioresource Technology 101 (18): 6930-4.

Xu, Q., Y. Zhang, J. Mo, and X. Li. 2011. “Indoor Formaldehyde Removal by Thermal Catalyst: Kinetic Characteristics, Key Parameters, and Temperature Influence." Environmental Science \& Technology 45 (13): 5754-60.

Xu, Q., W. Lei, X. Li, X. Qi, J. Yu, G. Liu, J. Wang, and P. Zhang. 2014 a. "Efficient Removal of Formaldehyde by Nanosized Gold on WellDefined $\mathrm{CeO}_{2}$ Nanorods at Room Temperature." Environmental Science \& Technology 48 (16): 9702-8.

Xu, Q., W. Lei, X. Li, X. Qi, J. Yu, G. Liu, J. Wang, and P. Zhang. 2014b. "Efficient Removal of Formaldehyde by Nanosized Gold on WellDefined $\mathrm{CeO}_{2}$ Nanorods at Room Temperature." Environmental Science \& Technology 48 (16): 9702-8.

Yamashita, H., M. Honda, M. Harada, Y. Ichihashi, M. Anpo, T. Hirao, N. Itoh, and N. Iwamoto. 1998. "Preparation of Titanium Oxide Photocatalysts Anchored on Porous Silica Glass by a Metal IonImplantation Method and Their Photocatalytic Reactivities for the Degradation of 2-propanol Diluted in Water." The Journal of Physical Chemistry B 102 (52): 10707-11.

Yang, L., and Z. Liu. 2007. "Study on Light Intensity in the Process of Photocatalytic Degradation of Indoor Gaseous Formaldehyde for Saving Energy." Energy Conversion and Management 48 (3): 882-9.

Yang, J., D. Li, Z. Zhang, Q. Li, and H. Wang. 2000. "A Study of the Photocatalytic Oxidation of Formaldehyde on $\mathrm{Pt} / \mathrm{Fe}_{2} \mathrm{O}_{3} / \mathrm{TiO}_{2}$." Journal of Photochemistry and Photobiology A: Chemistry 137 (2): 197-202.

Yang, S., W. Zhu, Z. Jiang, Z. Chen, and J. Wang. 2006. "The Surface Properties and the Activities in Catalytic Wet Air Oxidation over $\mathrm{CeO}_{2}-\mathrm{TiO}_{2}$ Catalysts." Applied Surface Science 252 (24): 8499-505.

Yang, L., Z. Liu, J. Shi, Y. Zhang, H. Hu, and W. Shangguan. 2007. "Degradation of Indoor Gaseous Formaldehyde by Hybrid VUV and $\mathrm{TiO}_{2} /$ UV Processes." Separation and Purification Technology 54 (2): 204-11.

Yang, K., J. Liu, R. Si, X. Chen, W. Dai, and X. Fu. 2014. "Comparative Study of $\mathrm{Au} / \mathrm{TiO}_{2}$ and $\mathrm{Au} / \mathrm{Al}_{2} \mathrm{O}_{3}$ for Oxidizing $\mathrm{CO}$ in the Presence of $\mathrm{H} 2$ under Visible Light Irradiation." Journal of Catalysis 317: 229-39.

Yentekakis, I. V., G. Moggridge, C. G. Vayenas, and R. M. Lambert. 1994. "In Situ controlled Promotion of Catalyst Surfaces via NEMCA: The Effect of Na on the Pt-Catalyzed CO Oxidation." Journal of Catalysis 146 (1): 292-305.

Yi, N., R. Si, H. Saltsburg, and M. Flytzani-Stephanopoulos. 2010a. "Active Gold Species on Cerium Oxide Nanoshapes for Methanol Steam Reforming and the Water Gas Shift Reactions." Energy \& Environmental Science 3 (6): 831-7.

Yi, N., R. Si, H. Saltsburg, and M. Flytzani-Stephanopoulos. 2010b. "Steam Reforming of Methanol over Ceria and Gold-Ceria Nanoshapes." Applied Catalysis B: Environmental 95 (1): 87-92.

Yu, X., J. He, D. Wang, Y. Hu, H. Tian, and Z. He. 2011. "Facile Controlled Synthesis of Pt/ $\mathrm{MnO}_{2}$ Nanostructured Catalysts and Their Catalytic Performance for Oxidative Decomposition of Formaldehyde." The Journal of Physical Chemistry C 116 (1): 851-60.

Yu, X., J. He, D. Wang, Y. Hu, H. Tian, T. Dong, and Z. He. 2013. "Preparation of $\mathrm{Au} 0.5 \mathrm{Pt} 0.5 / \mathrm{MnO}_{2} /$ Cotton Catalysts for Decomposition of Formaldehyde." Journal of Nanoparticle Research 15 (8): 1832. 
Yuan, J., P. Xu, J. Wang, W. Zhang, J. Zhou, A. Lai, and L. Wang. 2020. "Experimental Study on the Removal of Formaldehyde by Plasma-Catalyst." In IOP Conference Series: Earth and Environmental Science, vol. 435, no. 1, 012004.

Zang, L., W. Macyk, C. Lange, W. F. Maier, C. Antonius, D. Meissner, and H. Kisch. 2000. "Visible-light Detoxification and Charge Generation by Transition Metal Chloride Modified Titania." Chemistry: $A$ European Journal 6 (2): 379-84.

Zazueta, A. L., H. Destaillats, and G. L. Puma. 2013. "Radiation Field Modeling and Optimization of a Compact and Modular Multi-Plate Photocatalytic Reactor (MPPR) for Air/water Purification by Monte Carlo Method." Chemical Engineering Journal 217: 475-85.

Zhai, Y., D. Pierre, R. Si, W. Deng, P. Ferrin, A. U. Nilekar, G. Peng, J. A. Herron, D. C. Bell, H. Saltsburg, and M. Mavrikakis. 2010. "Alkali-Stabilized Pt-OH ${ }_{x}$ Species Catalyze Low-Temperature Water-Gas Shift Reactions." Science 329 (5999): 1633-6.

Zhang, C. B., and H. He. 2005. "Elimination of Formaldehyde over Cu$\mathrm{Al}_{2} \mathrm{O}_{3}$ Catalyst at Room Temperature." Journal of Environmental Sciences 17 (3): 429-32.

Zhang, C., and H. He. 2007. "A Comparative Study of $\mathrm{TiO}_{2}$ Supported Noble Metal Catalysts for the Oxidation of Formaldehyde at Room Temperature." Catalysis Today 126 (3): 345-50.

Zhang, C., H. He, and K. I. Tanaka. 2005. "Perfect Catalytic Oxidation of Formaldehyde over a Pt/ $\mathrm{TiO}_{2}$ Catalyst at Room Temperature." Catalysis Communications 6 (3): 211-4.

Zhang, C., H. He, and K. I. Tanaka. 2006. "Catalytic Performance and Mechanism of a Pt/TiO ${ }_{2}$ Catalyst for the Oxidation of Formaldehyde at Room Temperature." Applied Catalysis B: Environmental 65 (1): 37-43.

Zhang, Z., O. Bondarchuk, B. D. Kay, J. M. White, and Z. Dohnálek. 2007. "Direct Visualization of 2-Butanol Adsorption and Dissociation on $\mathrm{TiO}_{2}$ (110)." The Journal of Physical Chemistry $C$ 111 (7): 3021-7.

Zhang, C., F. Liu, Y. Zhai, H. Ariga, N. Yi, Y. Liu, K. Asakura, M. FlytzaniStephanopoulos, and H. He. 2012. “Alkali-Metal-Promoted Pt/ $\mathrm{TiO}_{2}$ Opens a More Efficient Pathway to Formaldehyde Oxidation at Ambient Temperatures." Angewandte Chemie International Edition 51 (38): 9628-32.

Zhang, C., Y. Li, Y. Wang, and H. He. 2014. "Sodium-promoted Pd/TiO for Catalytic Oxidation of Formaldehyde at Ambient
Temperature.” Environmental Science \& Technology 48 (10): 5816-22.

Zhang, J., Y. Li, Y. Zhang, M. Chen, L. Wang, C. Zhang, and H. He. 2015a. "Effect of Support on the Activity of Ag-Based Catalysts for Formaldehyde Oxidation." Scientific Reports 5.

Zhang, S., X. S. Li, B. Zhu, J. L. Liu, X. Zhu, A. M. Zhu, and B. W. Jang. 2015b. "Atmospheric-Pressure $\mathrm{O}_{2}$ Plasma Treatment of $\mathrm{Au} / \mathrm{TiO}_{2}$ Catalysts for CO Oxidation." Catalysis Today 256: 142-7.

Zhang, Z., Z. Jiang, and W. Shangguan. 2016. "Low-temperature Catalysis for VOCs Removal in Technology and Application: a State-of-the-Art Review." Catalysis Today 264: 270-8.

Zhang, S., M. Wang, Z. Lu, C. Ma, and W. Jia. 2019. "Biomass Bricks with Excellent Indoor Formaldehyde Capture and Transformation Performance." ACS Sustainable Chemistry \& Engineering 7 (13): 11493-9.

Zhao, J., and X. Yang. 2003. "Photocatalytic Oxidation for Indoor Air Purification: a Literature Review." Building and Environment 38 (5): 645-54.

Zhao, W., W. Ma, C. Chen, J. Zhao, and Z. Shuai. 2004. "Efficient Degradation of Toxic Organic Pollutants with $\mathrm{Ni}_{2} \mathrm{O}_{3} / \mathrm{TiO}_{2-x} \mathrm{~B}_{x}$ under Visible Irradiation." Journal of the American Chemical Society 126 (15): 4782-3.

Zhao, D. Z., C. Shi, X. S. Li, A. M. Zhu, and B. W. Jang. 2012. “Enhanced Effect of Water Vapor on Complete Oxidation of Formaldehyde in Air with Ozone over $\mathrm{MnO}_{x}$ Catalysts at Room Temperature." Journal of Hazardous Materials 239: 362-9.

Zhou, K., and Y. Li. 2012. "Catalysis Based on Nanocrystals with WellDefined Facets." Angewandte Chemie International Edition 51 (3): 602-13.

Zhu, Z., and R. J. Wu. 2015. "The Degradation of Formaldehyde Using a Pt@ $\mathrm{TiO}_{2}$ Nanoparticles in Presence of Visible Light Irradiation at Room Temperature." Journal of the Taiwan Institute of Chemical Engineers 50: 276-81.

Zhu, X., M. Shen, L. L. Lobban, and R. G. Mallinson. 2011. "Structural Effects of $\mathrm{Na}$ Promotion for High Water Gas Shift Activity on Pt$\mathrm{Na} / \mathrm{TiO}_{2}$." Journal of Catalysis 278 (1): 123-32.

Zou, L., Y. Luo, M. Hooper, and E. Hu. 2006. "Removal of VOCs by Photocatalysis Process Using Adsorption Enhanced $\mathrm{TiO}_{2}-\mathrm{SiO}_{2}$ Catalyst." Chemical Engineering and Processing: Process Intensification 45 (11): 959-64. 